\title{
SISTEMA DE ARRENDAMENTO DE TERRAS NO SETOR SUCRO-ALCOOLEIRO DO ESTADO DE SAOO PAULO
}

LUIZ ANTONIO CORREIA MARGARIDO

Orientador: FERNANDO CURI PERES

\begin{abstract}
Dissertação apresentada à Escola Superior de Agricultura "Luiz de Queiroz", da Universidade de São Paulo, para obtenção do título de Mestre em Agronomia, Ārea de Concentração em "Economia Agrāria".
\end{abstract}

$P$ I $R$ A C I C A B A

Estado de São Paulo - Brasil

Novembro, 1987 
ii.

Aos meus filhos: Tatyana e Felype 


\section{A GRA D E C I MEN T O S}

Ao Professor Dr. Fernando Curi Peres pela orientação na exe cução deste trabalho.

Ao Programa Nacional de Melhoramento da Cana-de-Açúcar - PIA NALSUCAR, pela oportunidade oferecida para a realização do Curso de pós Graduação.

As Unidades industriais do setor sucro-alcooleiro que colaboraram para a realização deste estudo.

Ass Sras. Maria Luisa Finardi Mazetto e Giovana Regina de Mo raes Bellon respectivamente pela tradução para $\circ$ Inglês e serviços de datilografia.

$\bar{A}$ todos que, direta ou indiretamente, colaboraram para a realização deste trabalho. 


\section{N D I C E}

Pàg.

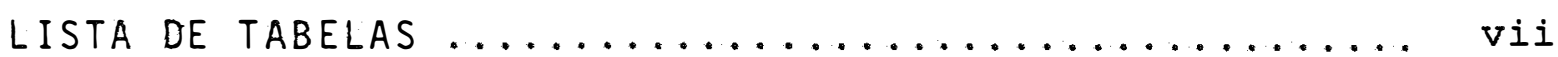

LISTA DE FIGURAS $\ldots \ldots \ldots \ldots \ldots \ldots \ldots \ldots \ldots \ldots \ldots \ldots \ldots \ldots \ldots \ldots \ldots \ldots \ldots \ldots$

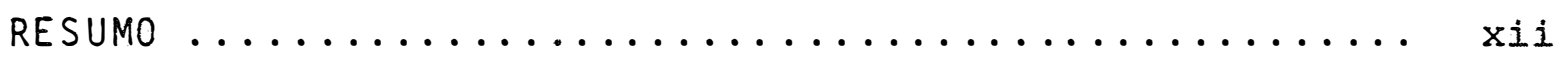

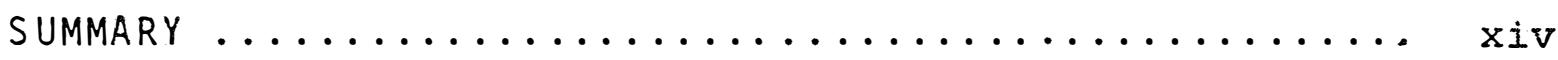

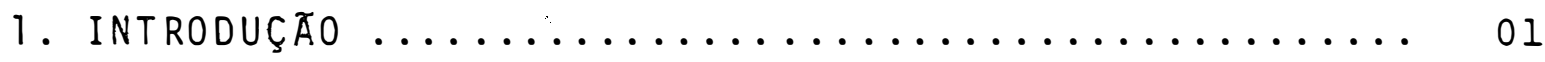

1.1. A Importāncia da Cuitura da Cana-de-Açúcar no Setor Agrícola do Estado de São Paulo ......... 02

1.2. Arrendamento de Terras no Estado de São Pau

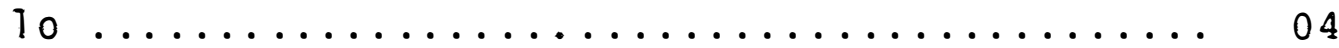

1.2.1. O Arrendamento de Terras pelas Usinas

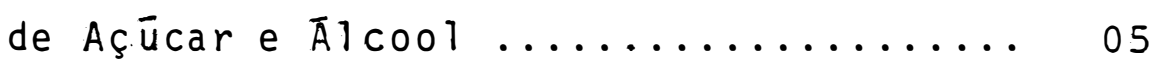

1.2.2. O Arrendamento como Remuneração da Ter-

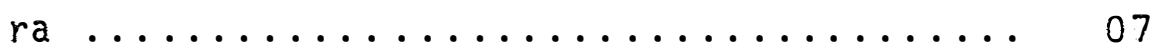

1.2.3. Arrendamento e o Risco .............. 11

1.3. Economias de Tamanho ................... 12

1.4. Sintese do Problema e Objetivo ............. 15

1.5. Hipötese .......................... 16

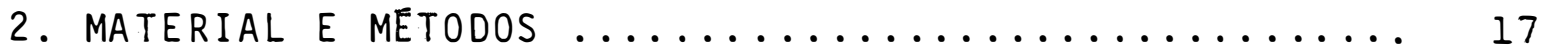

2.1. Caracterização da Ārea de Estudo ............ 17

2.2. Amostragem ......................... 21

2.3. Modelo Teörico ....................... 22

2.3.1. Modelo para Remuneração da Terra Arren

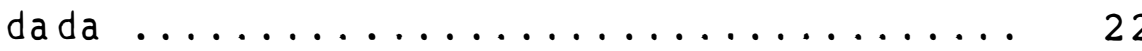


2.3.2. Modelo para Remuneração da Terra e do Produtor Autónomo Fornecedor de Cana-deAçūcar para as $U / D \ldots \ldots \ldots \ldots \ldots \ldots . \ldots \ldots$

3. PROCEDIMENTO ADOTADO NO LEVANTAMENTO DOS DADOS $\ldots . .27$

3.1. Unidades Industriais Levantadas ........... 27

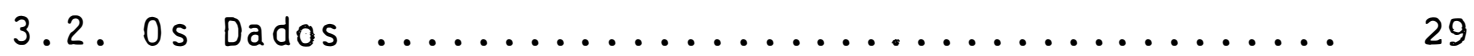

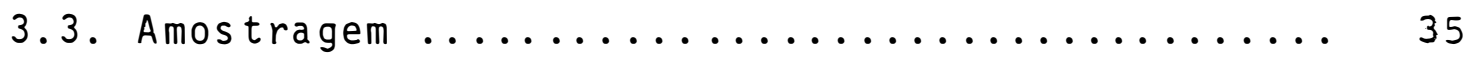

4. RESULTADOS E DISCUSSOES .................. 40

4.1. Cláusulas Principais dos Contratos de Arrenda-

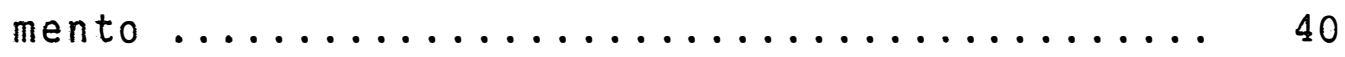

4.2. Remuneração da Terra Arrendada ............ 42

4.2.1. Região de Ribeirão Preto ........... 43

4.2.2. Região de Arenito e Vale do Paranapane

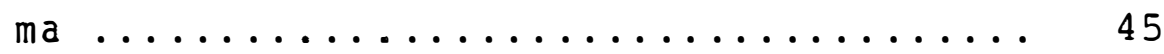

4.2.3. Região de Jaū e Araraquara .......... 48

4.2.4. Região de Piracicaba ............. 50

4.3. Remuneração do Produtor Autōnomo Proprietārio

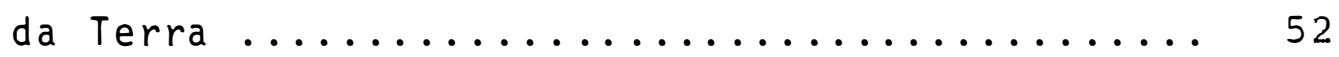

4.4. Determinação da Distāncia à Unidade Industrial que Nivela a Remuneração Obtida com o Arrendamento de Terras com a Produção Autōnoma ...... 54 4.4.1. Região de Ribeirão Preto ............ 54 4.4.2. Região de Arenito e Vale do Paranapane

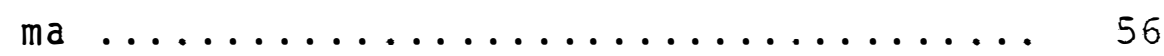

4.4.3. Região de Jaū e Araraquara .......... 57 
vi.

Pāg.

4.4.4. Região de Piracicaba ............ 59

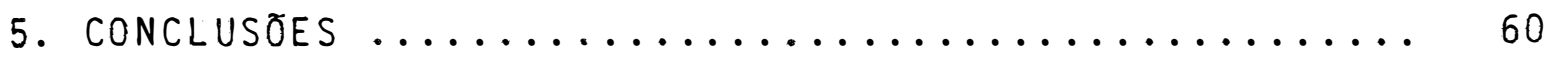

6. LITERATURA CITADA ....................... 64

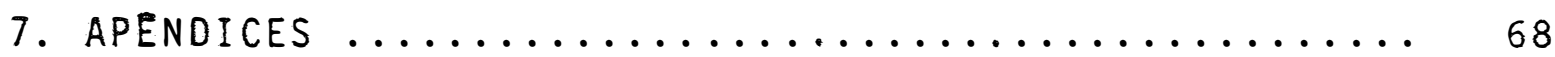




\section{LISTA DE TABELAS}

Päg.

Tabela 1. Evolução da ārea cultivada com cana-deaçūcar no Estado de São Paulo .............

Tabela 2. Número de unidades de cada região produtora do Estado de São Paulo seguindo critêrio adotado pelo IAA/PLANALSUCAR para realização da Estimativa da Safra $85 / 86$........... 20

Tabela 3. A ārea de corte de cana-de-açūcar nas respectivas regiões produtoras do Estado de São Paulo na safra $85 / 86 \ldots \ldots \ldots \ldots \ldots$

Tabela 4. Critério adotado para a classificação dos solos arrendados, de acôrdo com a topografia e fertilidade apresentadas ...........

Tabela 5. Realização ou não do arrendamento nas usinas e destilarias que declararam intenção de moagem na safra $86 / 87$, por região produ-

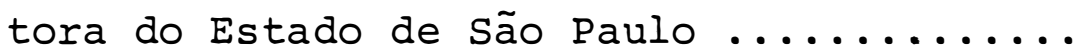

Tabela 6. Āreas de arrendamento (ha) declarada pelas usinas e destilarias durante a safra $86 / 87$ nas regiões produtoras do Estado de São Pau

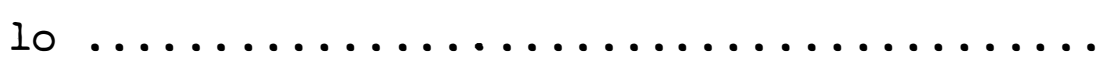


Tabela 7. Participação da ārea arrendada (A.A.) no to tal da área cultivada (A.C.) com cana-de-a çūcar, por região produtora do Estado de São Paulo na safra $86 / 87 \ldots \ldots \ldots \ldots \ldots$.

Tabela 8. Média $(\bar{x})$ e desvio padrão $(\sigma)$ da razão entre área arrendada e కrea cultivada com cana-de-açũcar nas unidades que declararam realizar o arrendamento no Estado de são Paulo na safra $86 / 87 \ldots \ldots \ldots \ldots \ldots \ldots$

Tabela 9. Årea mēdia arrendada pelas usinas e destila rias (ha) nas regiões produtoras do Estado de são Paulo durante a safra $86 / 87 \ldots \ldots$.

Tabela 10. Valores de arrendamento em toneladas por hectare ao ano nas diversas regiões produto

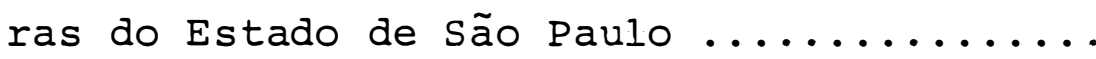

Tabela 11. Fatores levados em consideração para remune ração do arrendamento na Agroindústria sucro Alcooleira do Estado de são Paulo duran te a safra $86 / 87 \ldots \ldots \ldots \ldots \ldots \ldots \ldots$ 
Tabela 12. Número de unidades entrevistadas pessoalmen te nas regiões produtoras do Estado de São Paulo durante a safra $86 / 87 \ldots \ldots \ldots \ldots \ldots$

Tabela 13. Distribuição das propriedades arrendadas por região produtora de cana-de-açūcar do Estado de São Paulo durante a safra $86 / 87$..

Tabela 14. Estimativa da remuneração da terra arrendada no setor sucro alcooleiro para a região de Ribeirão Preto durante a safra $86 / 87 \ldots \ldots \ldots \ldots \ldots \ldots \ldots \ldots \ldots \ldots \ldots \ldots \ldots \ldots \ldots \ldots$

Tabela 15. Estimativa da remuneração da terra arrendada no setor sucro alcooleiro para a região de Arenito-Vale do Paranapanema durante a safra $86 / 87 \ldots \ldots \ldots \ldots \ldots \ldots \ldots$

Tabela 16. Estimativa da remuneração da terra arrendada no setor sucro alcooleiro para a região de Jaú-Araraquara durante a safra

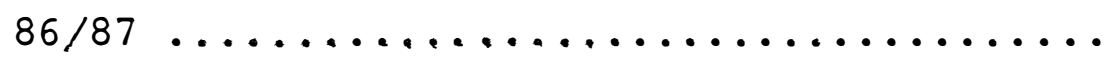


pàg.

Tabela 17. Estimativa da remuneração da terra arrendada no setor sucro alcooleiro para a região de Piracicaba durante a safra $86 / 87$.. 
xi.

\section{LISTA DE FIGURAS}

Pāg.

Figura 1. Regiões canavieiras do Estado de São Pau$10 \ldots \ldots \ldots \ldots \ldots \ldots \ldots \ldots \ldots \ldots \ldots \ldots \ldots \ldots . \ldots \ldots \ldots$ 
SISTEMA DE ARRENDAMENTO DE TERRAS NO SETOR SUCRO-ALCOOLEIRO

$$
\text { DO ESTADO DE SAOO PAULO }
$$

Autor: LUIZ ANTONIO CORREIA MARGARIDO

Orientador: FERNANDO CURI PERES

\section{R E S U M O}

A cultura da cana-de-açúcar sempre teve importância no setor agrícola e com o Programa Nacional do Álcool (PROALCOOL) iniciado em 1975 obteve um grande aumento de área plantada. São Paulo foi o estado da federação que teve - maior número de novas destilarias instaladas e a taxa de crescimento da área plantada com tal cultura foi 9,6\% ao ano durante o período de 1975 a 1985.

o arrendamento de terras que jā era uma prática tradicional no setor canavieiro foi a forma encontrada pelas novas destilarias para suprir a necessidade de matéria prima para indústria.

O objetivo do presente trabalho foi avaliar a remuneração das terras arrendadas para as usinas e destilarias, e fazer uma comparação com a remuneração obtida pelo fornecedor de cana-de-açūcar. 
As informações sobre o arrendamento foram conse guidas num levantamento realizado nas próprias unidades indus triais (usinas e destilarias), que tiveram intenção de moagem para a safra $86 / 87$ do Estado de São Paulo.

A área arrendada nessa safra somava aproximadamente 450.0.00 ha, representando cerca de $20 \%$ do total da cana cultivada no estado.

Os resultados sugerem que a remuneração obtida com $\circ$ arrendamento de terras durante a safra 86/87 quase sempre foi superior a remuneração obtida com a produção autônoma.

Este fato pode ser uma explicação para $\circ$ decréscimo que vem ocorrendo na participação de verdadeiros for necedores de cana no total de cana esmagada no estado. 
xiv.

LAND LEASE SYSTEM BY ALCOHOL AND SUGAR MILLS IN THE STATE OF SAO PAULO

Author: LUIZ ANTONIO CORREIA MARGARIDO

Adviser: FERNANDO CURI PERES

\section{$S U M M A R Y$}

The sugarcane culture, which always had an important roll in the agricultural sector, after the National Alcohol Program (PROALCOOL), initiated in 1975, achieved a large increase in the cultivated area. São Paulo is the Brazilian state with the highest number of installed destilleries and the rate of increase in the planted area with this culture was $9.6 \%$ per vear during the period from 1975 to 1985.

The land lease which was a common practice in the sugarcane sector was the means found by the new destilleries to supply their raw material demand.

The objective of this paper was to evaluate income from the land lease to sugarmills and destilleries, comparing it with that achieved with sugarcane production. Information concerning land lease was obtained through a survey carried out in the industrial unities (sugarmill and destilleries), which presented milling intention for the $86 / 87$ harvest in the state of são Paulo. 
The leased land in this harvest amounted to approximately 450,000 ha, representing about $20 \%$ of the total of sugarcane cultivated in the state.

Results suggest that the payments for the land lease during the $86 / 87$ harvest was almost always superior than income from independent production.

This fact may explain the decrease observed in the participation of real sugarcane producers in the total of milled cane in the state. 
1. INTRODUÇAO

A cultura da cana-de-açūcar, desde a época do Brasil colônia ocupa um lugar de destaque no setor agricola. Com a criação do Programa Nacional do Álcool (PROALCOOL) ini ciado em 1975 tal cultura obteve uma grande expansão de área plantada. O número de destilarias instaladas aumentou consideravelmente, principalmente no Estado de são Paulo, que è responsāvel por mais de cinquenta por cento da produção nacional de cana, açúcar e álcool.

Esse rápido crescimento do setor sucro-alcoolei ro, acarretou modificações tanto do ponto de vista tecnológico como também social, que foram sentidos em maior ou menor intensidade por toda sociedade. Como todo programa de grande dimensão, ele apresenta pontos positivos e negativos. Entre os pontos favoráveis mais comumente mencionados estão o número de empregos criados e a ação favorável na balança comercial, através de economia realizada com a diminuição de importą ção de petróleo. Entre os pontos negativos estão a diminui- 
ção da oferta de alimentos e o aspecto concentrador de renda do Programa. E comum se citar o arrendamento de terras como um dos agentes responsáveis por essa concentração, pois em ge ral o arrendamento antecede a compra da terra.

Esclarecer como funciona o arrendamento de ter ras no setor sucro-alcooleiro do Estado de São Paulo e analisar qual sistema de exploração que permite maiores lucros ao proprietário da terra, fornecedor de cana-de-açūcar, são os objetivos desse trabalho.

1.1. A Importāncia da Cultura da Cana-de-Açūcar no Setor Agrícola do Estado de São Paulo.

A cana-de-açūcar ocupa aproximadamente $30 \%$ da área de lavouras do Estado de São Paulo. Segundo IAA/PLANALSUCAR (1986) esta foi de 2.000 .950 ha na safra $85 / 86$.

Apesar de ser uma cultura com elevada exigência de mão-de-obra apenas em deteminados periodos (plantio e colheita), alguns estudos, como o de AZEVEDO et alii (1984) concluiram que $\circ$ PROÁLCOOL teve um efeito positivo sobre o nivel de emprego. Outros, como VEIGA FILHO et alii (1981), mostram que - saldo final dos empregos criados para as regiões de Ribei rão Preto e Campinas foram positivos, apesar de ter ocorrido o inverso nas regiões de Bauru e Marilia.

São Paulo é o Estado da federação que, além de ser o maior produtor de cana, açúcar e álcool, é também o que 
possui a maior produtividade agricola e industrial. Tal fato pode estar associado a fertilidade do solo e também ao grande número de entidades de pesquisa que atuam nesse Estado, pois o nỉvel tecnológico e gerencial ai empregado é bastante superior aos demais. Deve-se destacar também o importante papel das entidades dos fornecedores de cana na assistência técnica, difusão de tecnologia e comercialização de insumos. Pela grandeza do setor, pode-se ter uma estimativa da importância desta cultura como mercado para os insumos agrícolas. Destaca-se que no ano de 1984 esta cultura, segundo PROGNOSTICO (1985), foi responsável por 19,6\% do total de crédito de custeio concedido ao Estado.

Quanto aos fornecedores, que são produtores de cana-de-açúcar e que fornecem a matéria-prima para as usinas e destilarias (U/D), segundo a ORPLANA (1985) somam cerca de $12.000 \mathrm{em}$ todo o Estado. Uma amostra de fornecedores estudada por CARON (1984) na safra 81/82, mostrou que a grande maio ria tinha no fornecimento de cana-de-açúcar a sua principal fonte de renda. Uma das vantagens que os produtores desta cultura possuem è o reduzido risco que a cana-de-açúcar apresenta, quando comparada com outras culturas. Isto se deve tanto ao fato de os preços serem administrados pelo govêrno, co mo à característica agronômica da própria planta, a qual è pouco susceptivel a variações climáticas. 


\subsection{Arrendamento de Terras no Estado de São Paulo.}

Arrendamento é um sistema de posse e uso da ter ra em que o arrenđatário explora a terra pertencente a outra pessoa, a quem paga aluguel pelo seu uso e gozo. Tal sistema é regido pelo estatuto da terra (Lei no 4504 de 30/11/84) e pelo decreto no 59566 de $14 / 11 / 66$.

Muitas vezes o termo parceria é usado como sinô nimo ou tipo de arrendamento, mas convém ressaltar que a dife rença básica entre ambos é que na parceria, o aluguel corresponde a um determinado percentual da produção, enquanto no a rendamento, o aluguel é fixo, independente da quantidade produzida.

Um dos estudos pioneiros neste assunto foi o elaborado por CALDEIRA (1950) que analisou o arrendamento de terras no Brasil e em particular no Estado de são Paulo e no Rio Grande do Sul. Em São Paulo a queda dos preços do café e ascensão da cultura do algodão são apontados como fatores de relevância no surgimento do arrendamento. O mesmo autor (1955) também focalizou os diversos aspectos do arrendamento e da parceria no Brasil, destacando as formas de contratos, duração, modo de pagamento ou venda da produção. Destaca-se que na época, os contratos verbais eram bem mais frequentes que os contratos por escrito.

GARCIA (1982) realizou um estudo sobre arrendamento e parceria agrícola no Estado de são Paulo, no qual ana 
lisa os principais fatores que influenciaram na maior ou menor utilização deste ou daquele sistema ao longo dos anos, e a evolução destes no que diz respeito ao número de estabelecí mentos, área abrangida e formas de utilização da terra. Destaca também que até 1960 o arrendamento e a parceria autônoma foram os principais meios de acesso à terra para as camadas não proprietárias.

Atualmente, as informações sobre arrendamento de terras e parceria agrícola são baseados nos Censos Agropecuários editados pelo Instituto Brasileiro de Geografia e Estatistica. Segundo o CENSO AGROPECUÁRIO (1984) a soma das àreas arrendadas e de parceria agrícola perfazem cerca de $8 \%$ da ārea agrícola do Estado de São Paulo sendo que a cultura da cana-de-açúcar é aquela que tem maior participação nesse percentual, com cerca de 13\%. Acredita-se que devido a recen te expansão da fronteira canavieira, este percentual deva ter crescido.

1.2.1. O Arrendamento de Terras pelas Usinas de Açūcar e Alcool

Além dos dados divulgados pelo IBGE, pouco śe sabe sobre o arrendamento de terras no setor sucro-alcooleiro. Tal fato pode-se dever às dificuldades existentes no que diz respeito a obtenção das informações relacionadas com 0 assunto. Para esclarecer este ponto convém mencionar uma ex- 
periência obtida pelo PLANALSUCAR em uma pesquisa feita com fornecedores de cana-de-açūcar e relatada por CARON (1986).

"Problema mais grave foi o dos fornecedores que, tendo sido entrevistados no recinto da usina, na época de pagamento, deixaram de explicar que ali estavam para receber pe lo arrendamento da terra e não pela cana fornecida à usina. Assim, passaram a responder o questionário técnico como se fossem eles os "reais" cultivadores. As vacilações em muitas perguntas por um lado, e a extrema homogeneidade das técnicas que diziam adotar bem como sua identidade com aquelas adotadas pela usina, levou o entrevistador a descobrir que se tratava de rentistas e não de "reais" fornecedores de cana".

Este fato demonstra que os próprios proprietários de terra preferem não ser considerados arrendadores e sim fornecedores de cana para a usina, dificultando assim o acesso às informações.

outro ponto que também deve ser destacado, é que o arrendamento sempre foi considerado como um meio de acesso a terra daquele que não a possuia. BEskow (1986) cita o exemplo da cultura de arroz no Rio Grande do sul em que o regime do chamado arrendamento capitalista é caracterizado pe la participação de três classes sociais: os grandes proprietá rios, os arrendatários capitalistas e os assalariados rurais os quais produzem o excedente econômico que ê dividido em ren da fundiária e lucro dos arrendatários. O que acontece no se tor canavieiro não é bem assim, ou seja, a unidade industrial 
na condição de arrendatária e geralmente proprietária de gran des áreas sai a procura, das terras mais próximas do local de sua instalação. Se a compra desta não ocorre de imediato, es ta pode acontecer no médio e longo prazo, pois no contrato de arrendamento, o arrendatário tem prioridade na hora da compra, caso o proprietário queira vender suas terras.

1.2.2. O Arrendamento. como Remuneração da Terra

Com ○ PROÁLCOOL, muitas usinas aumentaram a sua capacidade industrial $e$, consequentemente, a sua necessidade de matéria-prima. Algumas adotaram a politica de compra de terras, enquanto que outras procuraram, através do arrendamen to, suprir esta necessidade.

Quanto o proprietário da terra, arrenda para as $U / D$, ele troca a remuneração que seria obtida com a produção agrícola pela remuneração obtida com $\circ$ arrendamento da terra. Sabe-se que o preço da terra está diretamente ligado ao valor da renda da terra ou do arrendamento. Muitos trabalhos de custo de Produção, tal como o de ORPLANA (1986), incluem o valor do arrendamento como forma de remunerar a terra. Outros, como o da FUNDAÇÃO GETULIO VARGAS (1983) fixam um determinado percentual sobre o valor desta.

PINHEIRO \& REYDON (1981) observaram que a taxa de crescimento do preço de venda foi superior à de crescimen- 
to do arrendamento para o período 1966 a 1978 no Estado de São Paulo. Esta constatação seria, segundo os autores, um elemento indicador de que hầ outros fatores externos à produção, que passaram de forma crescente a participar na formação do preço da terra. Destacaram a homogeneidade encontrada no comportamento dos preços reais da venda da terra, o que não é verificado no comportamento dos preços reais de arrendamento.

Segundo BRANDÃo (1986) o fato de não haver uma sincronização de aluguel da terra e seu preço não significa obrigatoriamente que outros retornos (de natureza não agrỉcola) estejam interferindo na formação do preço da terra. Segundo o autor, esta evidência pode apenas refletir os ajustą mentos das carteiras individuais às variações no nỉvel de atị vidade econômica. Cita também as limitações das análises que se concentram simplesmente na relação entre o aluguel e o pre ço da terra quando se considera uma taxa de desconto constante. Isto implica, segundo o autor, em desconsiderar aspectos importantes do comportamento da economia e dos agentes econômicos, tais como o ciclo e os riscos.

Segundo SAYAD (1982) a terra representa, para di versas economias, uma reserva de valor. Assim, além do lucro gerado na produção de produtos agrỉcolas, a expectativa de variação de preços assume papel fundamental na determinação do preço corrente. Também a valorização da terra e a evo 
lução da relação de trocas entre a agricultura e a indústria devem ser considerados. Segundo OLIVEIRA \& COSTA (1977) toda politica que visar uma relação de preço favorável a agricultü ra, ou conceder estímulos para a adoção de tecnologias que au mentam a produtividade da terra trará consigo também um aumen to do preço real da terra.

Acredita-se que na ausência de um mercado de ca pitais suficientemente forte, e que inspire confiança a longo prazo, alguns indivíduos podem usar imóveis como reserva de valor, especialmente em situações inflacionārias. Na ausência de distorções ou interferências governamentais e com o funcionamento do mercado de capitais, è de se esperar que o preço da terra guarde estreita relação com a renda da terra ou o arrendamento.

o que deve ser enfatizado é que as terras locali zadas ao redor das unidades industriais são de grande interesse para estas, porque quanto mais próxima ficar a produção da matéria prima da indústria, menores os gastos com transporte, que è um componente de muita importância no custo total da tonelada de cana-de-açúcar. Levando-se em consideração a maior infraestrutura e tecnologia existente nas U/D, estas podem obter uma maior produtividade do que o produtor isolado, e oferecer um preço por hectare maior do que o do mercado, ou pro por um sistema de arrendamento em que a remuneração da terra seja atrativa. Tambēm deve ser lembrado que as U/D obtēm lucro no setor industrial (açūcar e álcool) fazendo com que a 
parte agrícola fornecedora de matéria prima possa até ser cul tivada em niveis acima do ótimo econômico no curto prazo, pois isto pode ser compensado através do lucro industrial, já que o preço da cana é fixado exogenamente. Assim, a decisão de comprar ou arrendar a terra, depende da politica adotada pelas U/D e pela existência ou não de facilidades de crédito ou disponibilidade de caixa.

Já o proprietário das terras prōximas às U/D, tem as seguintes opções:

- Plantar outras culturas;

- Plantar cana-de-açúcar e entregar a produção as $U / D$;

- Vender suas terras;

- Arrendar suas terras para as U/D.

A primeira alternativa geralmente é descartada, pelas vantagens que a cana-de-açúcar oferece. Quanto as outras três, é lógico que o proprietário da terra tem a liberda de para qual usina ou destilaria entregar a sua produção, ven der ou arrendar sua propriedade. Acontece que a única que po de oferecer um maior preço, tanto pela compra ou pelo arrenda mento, é aquela que lhe está mais próxima. Este fato faz com que exista um certo poder monopsonístico por parte das U/D que definem até que preço elas podem pagar. Se o proprietário da terra resolver atuar no setor produzindo por conta própria, deve considerar que sua remuneração também vai decrescer com 
- aumento da distância percorrida, pois o gasto com 0 trans porte da produção vai depender desta. Assim, pode ser mais vantajoso para o fornecedor arrendar a sua terra para as U/D e receber uma remuneração fixa, podendo dedicar o seu tempo para outros fins. Por outro lado para as U/D O arrendamento de terras representa uma alternativa para assegurar o forneci mento de matéria prima, sem necessidade de grandes investimen tos, adicionais pois a maioria já possui uma grande infra estru tura formada no setor agricola.

\subsubsection{Arrendamento e o Risco}

Tradicionalmente é conhecido o fato deoarrendamento ser usado como forma de minimizar o risco. Segundo FER REIRA (1979), os contratos de arrendamento agrícola podem ser definidos como instrumentos institucionais para alocar o risco entre donos de terra e arrendatários. Aluguéis em dinheiro, pagos antes ou independentemente da produção, implicam que os riscos são assumidos inteiramente pelos arrendatários, ao passo que os contratos de parceria distribuem os riscos entre arrendatários e os proprietários em proporções determinadas.

No caso da cultura da cana-de-açúcar, o fator risco também deve estar presente quando o proprietário da ter ra decide arrendar para a $U / D$, mas acredita-se que num nivel 
menor que quando comparado com outras culturas. Tal fato deve-se ao controle de preço fixado pelo governo e pelas caracteristi cas agronômicas da cultura, já citadas anteriormente. Por es te motivo o fator risco não será aqui considerado, mas devese estar ciente que em algum grau, ele também deve estar sendo considerado na hora deoproprietário da terra optar pelo ar rendamento.

\subsection{Economias de Tamanho}

E sabido que as U/D possuem uma maior infraestrutura que os fornecedores, que consiste em máquinas e equipamentos, e também de um quadro técnico especializado. É de se esperar que toda esta infraestrutura permita a U/D, na condição de arrendatária, obter um rendimento agrícola maior do que os fornecedores. PINAZZA \& PELIN (1981) mencionam que é reconhecido pela maioria, que a cultura da cana-de-açúcar é uma das poucas que apresenta ganhos quando se aumenta a escala de produção.

Uma das vantagens que as U/D possuem para aumen tar a produtividade por área plantada é poder contar nas àreas próximas com a aplicação de sub-produtos, como por exemplo a vinhaça e torta de filtro. Em geral as áreas próximas das unidades industriais pertencem as U/D, ou são arrendadas por estas, portanto a aplicação destes sub-produtos quase nun ca acontecem em áreas de fornecedores, pois o custo de trans 
porte limita a aplicação nas áreas mais distantes, quer sejam próprias, arrendadas ou mesmo de fornecedores que por ventura tenham interesse em tais sub-produtos. E lógico que esta dis tância de aplicação econômica é variāvel, podendo ser conside rada muito mais flexível para as terras sob controle das $U / D$, porque tal prática (utilização de sub-produtos) não è encarada somente sob o ponto de vista do aumento da produtividade agrícola mas também como uma solução para os problemas de des carte de resíduos da indústria que são altamente poluentes.

Importante também è o fato de a cultura da canade-açūcar exigir um preparo de solo quase sempre mais profundo do que as outras culturas devido ao intenso tráfego de má quinas pesadas durante a colheita, que faz com que seja neces sário o emprego de máquinas de maior porte ou potência. E 1ó gico que a aquisição dessas máquinas è mais fácil pelas usinas do que pelos produtores isolados. CLINE (1971) argumenta que poderia se esperar rendimentos crescentes de escala em paises de agricultura adiantada, pois certos implementos demandariam uma área mínima agrícola para serem totalmente utilizadas. Acredita-se que a Agricultura praticada no setor ca navieiro, principalmente no Estado de São Paulo possa ser classificada como adiantada e possa permitir a ocorrência de economias de tamanho.

Segundo BARBOSA, citado por FERREIRA (1979) foram estimados, para diversas funções de produção, os benefí cios e custos potenciais relacionados à reforma agrária, e re 
tornos constantes da escala ocorreram no tocante a todas as culturas, exceto à cana-de-açūcar.

Tambēm HOFFMAN (1981) cita vários trabalhos mos trando que o custo médio por tonelada, de algumas operações de produção de cana-de-açúcar, diminuì com a escala de produção. A colheita mecânica é citada pelo autor, como um exemplo em que ocorre economia de escala. A existência dessas economias pode ser um dos pontos que fazem com que o proprietário de terras deixe de produzir por conta própria e arrende suas terras para as usinas. Tambēm são conhecidas as economias pecuniárias que as grandes propriedades, no caso as Unidades Industriais, obtēm na compra de insumos, máquinas e implementos, o que sem dúvida também representa uma grande fonte de economia. Nesse sentido CHABARIBERY \& MELLO (1980) ons tataram que o custo de produção da tonelada de cana-de-açúcar obtido pelas usinas, durante a safra $80 / 81$ no Estado de são Paulo nas regiões de Piracicaba e Ribeirão Preto foi significativamente menor do que o custo obtido pelos fornecedores, mesmo considerando que os preços dos insumos tentra sido o mesmo para ambas as categorias, o que sem dúvida super estima o custo da usina.

E verdade que as vantagens obtidas com a escala de produção, tambēm poderiam beneficiar o pequeno produtor, se houvesse um sistema cooperativo que se preocupasse em prestar serviços agrícolas, como por exemplo o plantio e colheita, paa ra seus associados. Ocorre que na realidade isto praticamen- 
te não acontece no setor sucro-alcooleiro. Em trabalho recen te realizado por CARON e PINAZZA (1986) de todas as Cooperati vas de Fornecedores de Cana do Estado de São Paulo, apenas a Cooperativa dos Plantadores de Cana de Lençóis Paulista se preocupa com a mecanização das áreas dos cooperados. Outros estudos como MANOEL (1985) e RAMOS (1983) rejeitam a maior eficiência das grandes propriedades e argumentam que na realidade o que existe é uma política que favorece a uma maior concentração. No caso do setor sucro-alcoo leiro poderiam existir as duas situações, ou seja, uma maior eficiência por parte das grandes propriedades (usinas) e também uma política favorável a estas. As evidências, no entanto, não corroboram esta hipótese. A mesma política agrícola, especialmente a de crédito subsidiado, esteve disponível para as demais agroindústrias tais como as do fumo, tomate e chá.

\subsection{Sintese do Problema e Objetivo.}

Com o desenvolvimento do PROÁLCOOL ocorreu uma corrida das U/D do Estado de São Paulo em busca de terras agri cultáveis. Devido às economias de tamanho, estas podem obter uma maior produtividade por hectare $e$, consequentemente, um menor custo da tonelada de cana produzida. Assim, pode ser possivel arrendar a terra de terceiros e ainda pagar um aluguel que seja atraente para o proprietário desta.

Estudos já foram realizados evidenciando o as- 
pecto da concentração que existe no setor. Tais estudos, ape sar de importantes, se prendem ao aspecto sociológico e politico do problema, e não ajudam o proprietário de terra que queira atuar no setor sucro-alcooleiro, a tomar a decisão que The é mais vantajosa sob o ponto de vista econômico.

o objetivo do presente estudo é analisar o sistema de arrendamento de terras no setor sucro-alcooleiro do Estado de São Paulo, permitindo ao proprietário de terras visualizar qual sistema de exploração (arrendamento ou produção autônoma) lhe permite maiores vantagens econômicas.

\subsection{Hipōtese}

A hipótese fundamental é que a remuneração obtị da com o arrendamento de terras seja maior do que a remunera ção obtida com a produção autônoma.

Espera-se que a remuneração da terra arrenda da dependa da fertilidade, topografia e da distância em que a propriedade se encontra da usina.

A remuneração deve ser diretamente proporcional ao indice de fertilidade do solo e inversamente, à distância. Com um modelo de remuneração das terras arrendadas definido, será possível, para cada região, a comparação com a remuneração do produtor autônomo. 
2. MATERIAL E METODOS

\subsection{Caracterização da Area de Estudo.}

- Estado de São Paulo conta atualmente com uma ārea agrícola de aproximadamente 20 milhões de ha. A área plantada com cana-de-açúcar na safra 85/86 foi de 2.000 .950 ha, sendo responsável pela produção de 7,6 bilhões de litros de álcool e 3,4 milhões de toneladas de açúcar. O número de unida des industriais era composto de 68 usinas com destilaria anexa, 5 usinas sem destilaria anexa e 66 destilarias autônomas.

A matéria prima (cana-de-açúcar) tem origem na cana própria pertencente as usinas e destilarias (U/D) e na cana de fornecedores.

O número de entidades de classe de fornecedores espalhadas pelo estado soma 18. Elas desempenham importante papel na assistência técnica.

A produtividade agrícola média do estado era de $62 \mathrm{t} / \mathrm{ha} / \mathrm{ano}$ sendo considerada a maior do Brasil. 
Nos últimos anos o crescimento da área plantada com cana-de-açúcar foi de $9,6 \%$ ao ano e sua evolução anual po de ser acompanhado na Tabela 1 .

Tabela 1. Evolução da área cultivada com cana-de-açúcar no Estado de São Paulo.

\begin{tabular}{lc}
\hline Ano & Area (ha) \\
\hline 1975 & 759.852 \\
1976 & 890.500 \\
1977 & 927.560 \\
1978 & 1.053 .338 \\
1979 & 1.145 .740 \\
1980 & 1.217 .900 \\
1981 & 1.346 .500 \\
1982 & 1.634 .700 \\
1983 & 1.836 .360 \\
1984 & 1.870 .300 \\
1985 & 2.000 .950 \\
\hline
\end{tabular}

Fonte: IAA/PLANALSUCAR: Relatório Anual (Diversos números).

Tradicionalmente o Estado é dividido em 6 regiões produtoras de cana-de-açúcar (Piracicaba, Araraquara, 
Ribeirão Preto, Arenito, Vale do Paranapanema e Jaū) sendo que atualmente, com a expansão do PROALCOOL estas regiões não são completamente distinta, ocorrendo algum grau de arbitrio para se definir em que região se encontra uma determinada uni dade (ver Figura 1).

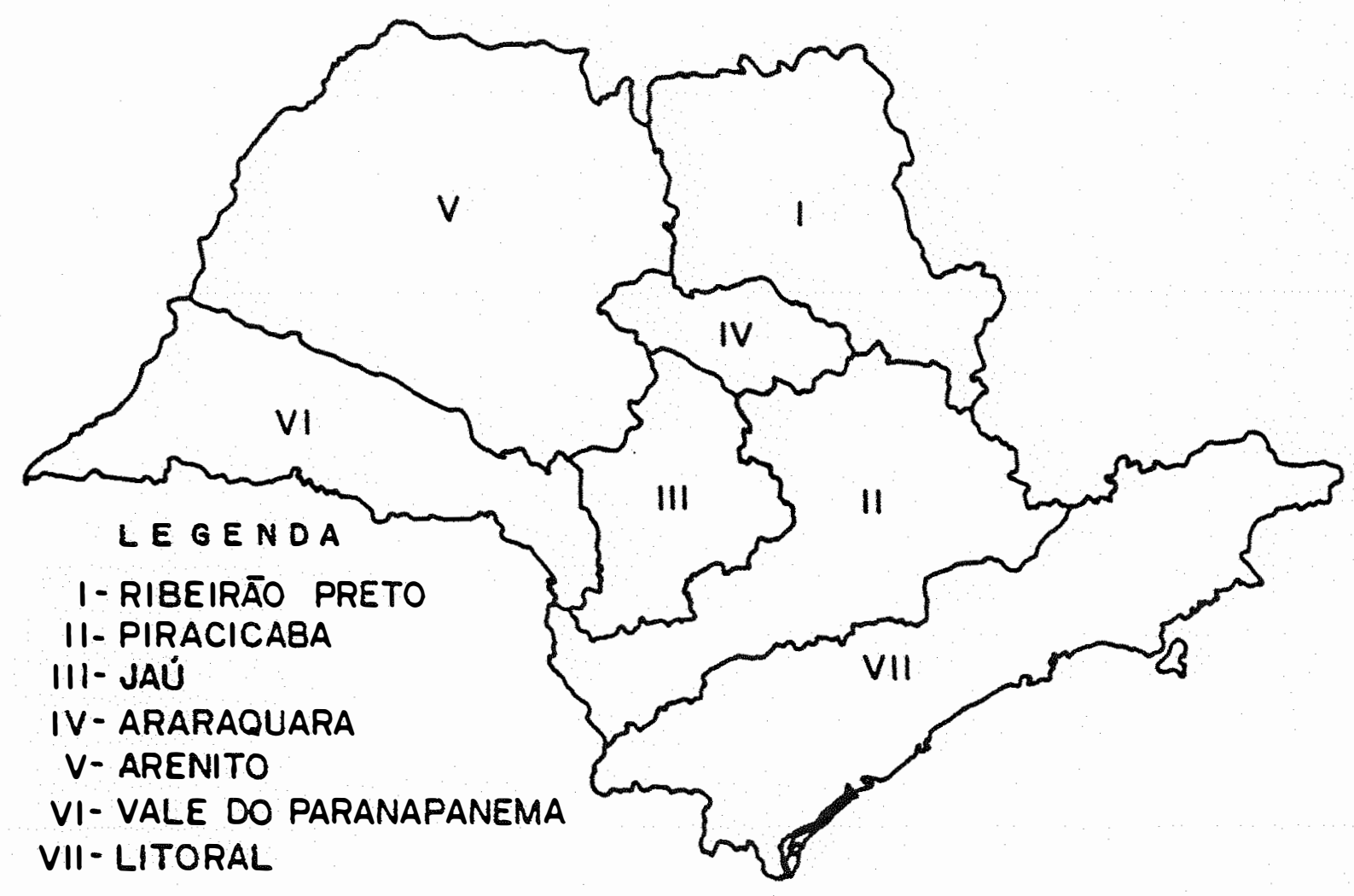

Figura 1. Regiões canavieiras do Estado de São Paulo. 
o número de unidades de cada região, segundo critério adotado pelo IAA/PLANALSUCAR (1985) para realização da Estimativa da Safra 85/86 encontra-se na Tabela 2.

Tabela 2. Número de unidades de cada região produtora do estado de São Paulo seguindo critério adotado pelo IAA/PLANALSUCAR para realização da Estimativa da Safra $85 / 86$.

\begin{tabular}{|c|c|c|c|}
\hline \multirow[b]{2}{*}{ Localização } & \multicolumn{3}{|c|}{ Número } \\
\hline & $\begin{array}{c}\text { Usina } \\
\text { C/s Destilaria } \\
\text { Anexa }\end{array}$ & $\begin{array}{c}\text { Destilaria } \\
\text { Autônoma }\end{array}$ & Total \\
\hline Ribeirão Preto & 21 & 16 & 37 \\
\hline Piracicaba & 27 & 05 & 32 \\
\hline Jaú & 07 & 03 & 10 \\
\hline Araraquara & 07 & 02 & 09 \\
\hline Arenito & 07 & 26 & 33 \\
\hline Vale do Paranapanema & 04 & 14 & 18 \\
\hline ESTADO DE SÃO PAULO & 73 & 66 & 139 \\
\hline
\end{tabular}

A área de corte nas respectivas regiões na Safra $85 / 86$ se encontra na Tabela 3 . 
Tabela 3. Ārea de corte de cana-de-açücar nas respectivas regiões produtoras do Estado de São Paulo na safra $85 / 86$.

Localização

Area de corte (ha)

Ribeirão Preto

$479.288,35$

Piracicaba

$373.315,24$

Jaú

$208.428,25$

Araraquara

$119.421,66$

Arenito

$250.617,27$

Vale do Paranapanema

$139.808,57$

ESTADO DE SÃO PAULO

$1.570 .879,34$

Fonte: Relatório Nacional da 3. Estimativa da Safra 85/86.

\subsection{Amostragem}

Neste estudo foram consideradas como regiões distintas apenas as seguintes: Ribeirão Preto, Piracicaba, Areni to e Jaú. Devido ao menor nümero de unidades e também por não apresentar uma diferenciação marcante, as regiões tra dicionais de Araraquara e do Vale do Paranapanema serão incluídas respectivamente nas regiões de Jaú e do Arenito. 
Primeiramente, para se obter uma visão preliminar da magnitude do arrendamento no setor, foi aplicado um questionārio simplificado em todas as unidades do estado, ficando-se sabendo quais as unidades de cada região que praticam $\circ$ arrendamento de terras. Posteriormente, com esta informação, foram contactadas as principais e realizada uma entrevista detalhada com o objetivo de levantar as informações necessárias para o estudo.

\subsection{Modelo Teōrico:}

2.3.1. Modelo para Remuneração da Terra Arrendada

Acredita-se que as principais variāveis que devem ser levadas em consideração sejam o tipo de solo em que se encontra a propriedade e a distância da unidade industrial. O tem po em que a unidade industrial está em atividade, também foi considerado. Isto pode ser captado considerando-se as usinas e destilarias separadamente, pois estas ültimas foram na sua totalidade recentemente instaladas e podem adotar outros critérios para remunerar as terras arrendadas.

Para a classificação do tipo de solo levou-se em consideração a fertilidade e topografia conforme Tabela 4 a seguir. 
Tabela 4. Critério adotado para a classificação dos solos ax rendados, de acôrdo com a topografia e fertilidade apresentadas.

\begin{tabular}{lcc}
\hline & \multicolumn{2}{c}{ Fertilidade } \\
\cline { 2 - 3 } Topografia & Alta & Baixa \\
\hline Plana & 4 & 2 \\
Ondulada & 3 & 1 \\
\hline
\end{tabular}

Fonte: Critério adotado pela pesquisa.

O modelo para cada região pode ser representado por:

$$
\mathrm{Y}_{j}=\alpha_{1}+\alpha_{2} \mathrm{X}_{2 j}+\alpha_{3} \mathrm{X}_{3 j}+\alpha_{4} \mathrm{X}_{4 j}+\gamma_{5} \mathrm{X}_{5 j}+\beta \mathrm{X}_{6 j}+\mu_{j}
$$

onde:

$$
\begin{aligned}
\mathrm{y}_{j} & =\text { remuneração da terra arrendada, em tonelada de cana/ha; } \\
\mathrm{x}_{2 j} & =1 \text { no tipo de solo } 2 \text { e zero para os demais; } \\
\mathrm{x}_{3 j} & =1 \text { no tipo de solo } 3 \text { e zero para os demais; } \\
\mathrm{x}_{4 j} & =1 \text { no tipo de solo } 4 \text { e zero para os demais; } \\
\mathrm{x}_{5 j} & =1 \text { para destilaria e zero para usina; } \\
\mathrm{x}_{6 j} & =\text { distância da unidade industrial em } \mathrm{Km} ; \\
\mu_{j} & =\text { perturbação estocāstica; } \\
j & =\text { número da observação. }
\end{aligned}
$$


De posse dos valores dos parâmetros estimados, pode-se aceitar ou rejeitar as hipóteses de que o valor do a rendamento varie conforme o tipo de solo e conforme a distância das unidades industriais, mostrando assim coerência ou in coerência nos contratos de arrendamento, tanto por parte das usinas quanto das destilarias. Espera-se valores positivos para $\alpha_{1}, \alpha_{2}, \alpha_{3}, \alpha_{4}$ pois tais parâmetros representam, respecti vamente, a remuneração do Solo I sem considerar o efeito da distância e os acréscimos decorrentes da melhora de topografia e de fertilidade. Quanto a $\beta$, este deve ser negativo, pois re presenta o decréscimo no valor de arrendamento à medida que se aumenta a distância da propriedade arrendada à unidade indus trial. O valor de $\gamma$ pode ser tanto positivo como negativo. Pa ra estimar os coeficientes de regressão foi utilizado o método dos minimos quadrados.

2.3.2. Modelo para Remuneração da Terra e do Produtor Autōnomo Fornecedor de Cana-de-Açūcar para as $U / D$

Esta remuneração seguirā o modelo conforme MAR GARIDO (1986) transformado para hectare plantado, cuja fömula geral è a seguinte:

$$
R P=Q \cdot P B-\{D D+[C t f(K m)]+D I+R C P\}
$$


onde:

$$
\begin{aligned}
R P= & \text { remuneração da terra e do produtor autônomo em } \\
& C z \$ / \text { ha; } \\
Q= & \text { produtividade agrìcola en toneladas por hectare plantado; } \\
\mathrm{PB}= & \text { preço bâsico da tonelada de cana, em Cz\$/ton; } \\
\mathrm{DD}= & \text { despesas diretas em } \mathrm{Cz} \$, \text { por ha, excluindo o custo } \\
& \text { de transporte; }
\end{aligned}
$$

Ctf $(\mathrm{Km})=$ custo do transporte da produção de um ha, variável com a distância, em $\mathrm{Cz} \$$;

$D I=$ despesas indiretas, em $C z \$ / h a$ excluindo os itens Re muneração de terra e Renda do proprietário;

$\mathrm{RCP}=$ remuneração ao capital fixo e circulante empregado por ha (medida pelo seu custo de oportunidade).

Por despesas diretas entende-se gastos com mãode-obra, combustivel e insumos efetivamente gastos na cultura.

Por despesas indiretas entende-se depreciação, administração, despesas gerais.

Este modelo representará a remuneração da terra, mais a remuneração do proprietário para um fornecedor representativo do Estado de São Paulo, pois ele é calculado ten do como referência o custo de produção da ORPLANA (1986). Para não correr o risco de se sub-estimar essa remuneração, será feito uma análise de sensibilidade, supondo-se a existência de um outro fornecedor, que seja mais eficiente ou capaz 
de obter uma produtividade 208 maior do que aquela encontrada pela ORPLANA, mas com os mesmos custos fixos. Tal procedi mento visa também contemplar aquele fornecedor cuja proprieda de se encontra sobre solos de melhor fertilidade. 


\subsection{Unidades Industriais Levantadas}

Todo $\circ$ ano 0 IAA/PLANALSUCAR realiza a estimati va da safra canavieira. Este levantamento consiste no envio de um questionário para todas as unidades industriais que pre tendem operar e posterior tabulação das informações obtidas. Durante $\bigcirc$ levantamento referente a safra $36 / 87$ para 0 Esta do de são Paulo foi também enviado um questionārio (Apêndice 1) com perguntas básicas sobre o arrendamento de terras.

O número total das unidades levantadas por região, assim como a quantificação daquelas que diziam realizar o arrendamento de terras pode ser visto na Tabela 5. 
Tabela 5. Realização ou não do arrendamento nas usinas e des tilarias que declararam intenção de moagem na safra $86 / 87$, por região produtora do Estado de São Paulo.

\begin{tabular}{|c|c|c|c|c|c|c|}
\hline \multirow{2}{*}{ Região } & \multicolumn{2}{|c|}{$\begin{array}{c}\text { Usinas } \\
\mathrm{C} / \mathrm{S} \text { Dest.Anexa }\end{array}$} & \multicolumn{2}{|c|}{$\begin{array}{l}\text { Destilarias } \\
\text { Autónomas }\end{array}$} & \multicolumn{2}{|c|}{ Total } \\
\hline & Sim & Não & Sim & Não & Sim & Não \\
\hline Ribeirão Preto & 12 & 8 & 9 & 10 & 21 & 18 \\
\hline Piracicaba & 20 & 6 & 4 & 3 & 24 & 9 \\
\hline Jaú e Araraquara & 9 & 5 & 4 & 3 & 13 & 8 \\
\hline Arenito e V. Paranapanema & 6 & 5 & 29 & 16 & 35 & 21 \\
\hline Estado de São Paulo & 47 & 14 & 46 & 32 & 93 & 46 \\
\hline$\%$ & 77 & 33 & 59 & 41 & 66 & 34 \\
\hline
\end{tabular}

Fonte: Dados da pesquisa.

Percebe-se (Tabela 5) que o arrendamento de terras é uma prática generalizada em cerca de $66 \%$ do total das unidades industriais que declararam intenção de moagem.e quando se analisa separadamente as usinas e destilarias este percentual passa para $77 \%$ e $59 \%$, respectivamente.

Apesar disso, suspeita-se de que estes números na realidade devam ser maiores, pois algumas unidades que sabidamente realizavam $\circ$ arrendamento de terras, por motivo ignorado, não declararam fazê-lo. Este fato merece algumas 
considerações adicionais.

Após o envio dos questionários, várias unidades procuraram O PLANALSUCAR preocupadas com a finalidade de tais informações. Outras perguntavam sobre o envolvimento do INCRA em tal estudo (na época do levantamento muito se falava do plano de reforma agrária). Estes fatos podem ter feito com que algumas unidades deixassem de fornecer informações ou que as subestimassem.

outra razão que tambēm pode ter agido no mesmo sentido é devido à grande concorrência por terras por parte de algumas usinas. Isto faz com que o assunto "arrendamento de terras" seja visto de maneira confidencial.

Finalmente, o fato do arrendamento de terras ser realizado em alguns locais por agropecuárias que, apesar de pertencerem ao mesmo grupo de usinas ou destilarias, podem tambēm não terem sido declarados, poìs o questionạrio foi enviado a essas ūltimas.

Mesmo com os problemas citados acima, acreditase que, pelo total da área declarada de arrendamento, obtevese uma boa aproximação do que representa tal prática nesse se tor.

3.2. Os Dados

As áreas de arrendamento das usinas e destila rias por região produtora podem ser vistos na Tabela 6 . 
Tabela 6. Áreas de arrendamento (ha) declarada pelas usinas e destilarias durante a safra $86 / 87$ nas regiões produtoras do Estado de São Paulo.

\begin{tabular}{lccc}
\hline \multicolumn{1}{c}{ Região/Área } & $\begin{array}{c}\text { Usina } \\
\text { C/S Dest. Anexa } \\
\text { (ha) }\end{array}$ & $\begin{array}{c}\text { Destilaria } \\
\text { Autônoma } \\
\text { (ha) }\end{array}$ & $\begin{array}{c}\text { Total } \\
\text { (ha) }\end{array}$ \\
\hline Ribeirão Pre to & 93.024 & 48.219 & 141.243 \\
Piracicaba & 96.478 & 26.620 & 99.140 \\
Jaú e Araraquara & 94.049 & 7.603 & 101.652 \\
Arenito e V. Paranapanema & 32.524 & 72.891 & 105.415 \\
\hline Estado de São Paulo & 316.075 & 131.375 & 447.450 \\
\hline
\end{tabular}

Fonte: Dados da pesquisa.

Percebe-se (Tabela 6) que as usinas são responsáveis por cerca de $71 \%$ da área declarada de arrendamento no Estado de São Paulo enquanto que as destilarias ficam com o restante.

A participação do arrendamento na área cultivada com cana-de-açúcar, separada em usina e destilaria nas regiões produtoras do Estado de são Paulo pode ser visto na Tabela 7 . 
Tabela 7. Participação da área arrendada (A.A.) no total da área cultivada (A.C.) com cana-de-açúcar, por região produtora do Estado de São Paulo na safra 86/87.

\begin{tabular}{lccc}
\hline Região & $\begin{array}{c}\text { Usina } \\
\text { C/S Dest.Anexa }\end{array}$ & $\begin{array}{c}\text { Destilaria } \\
\text { Autônoma }\end{array}$ & $\begin{array}{c}\text { Total } \\
\text { A.A./A.C. }\end{array}$ \\
\hline Ribeirão Preto & 0,19 & 0,35 & 0,23 \\
Piracicaba & 0,23 & 0,13 & 0,22 \\
Jaú e Araraquara & 0,23 & 0,39 & 0,23 \\
Arenito e V. Paranapanema & 0,16 & 0,25 & 0,21 \\
\hline Estado de são Paulo & 0,21 & 0,27 & 0,22 \\
\hline
\end{tabular}

Fonte: Dados da pesquisa.

Percebe-se pela Tabela 7, que as destilarias, apesar de possuirem menor área arrendada em valor absolü to, apresentam uma maior participação percentual no total plantado com cana.

As participações individuais das áreas arrenda das no total de cana plantada em cada unidade que praticou 0 arrendamento pode ser visto na Tabela 8 . 
Tabela 8. Média $(\bar{x})$ e desvio padrão $(\sigma)$ da razão entre ărea arrendada e área cultivada com cana-de-açúcar nas unidades que declararam realizar o arrendamento no Estado de São Paulo na safra $86 / 87$.

\begin{tabular}{|c|c|c|c|c|}
\hline \multirow{2}{*}{ Região } & \multicolumn{2}{|c|}{ Usina } & \multicolumn{2}{|c|}{ Destilaria } \\
\hline & $\bar{x}$ & $\sigma$ & $\bar{x}$ & $\sigma$ \\
\hline Ribeirão Preto & 0,32 & 0,20 & 0,68 & 0,28 \\
\hline Piracicaba & 0,23 & 0,16 & 0,23 & 0,09 \\
\hline Jaú e Araraquara & 0,31 & 0,20 & 0,54 & 0,30 \\
\hline Arenito e V. Paranapanema & 0,26 & 0,17 & 0,31 & 0,25 \\
\hline
\end{tabular}

Fonte: Dados da pesquisa.

Percebe-se (Tabela 8) que a participação do arrendamento nas unidades que declararam fazê-lo é bastante significativa, principalmente nas destilarias da Região de Ri. beirão Preto. Isto demonstra a importância do arrendamento de terras nessas regiões. E é uma evidência de que o PROÁLCOOL estimulou tal prática, pois em todas as regiões, com ex ceção de Piracicaba, a participação do arrendamento é bastante superior nas destilarias.

A área média do arrendamento pode ser visto na Tabela 9. 
Tabela 9. Srea média arrendada pelas usinas e destilarias(ha) nas regiões produtoras do Estado de São Paulo durante a safra $86 / 87$.

\begin{tabular}{lcc}
\hline \multicolumn{1}{c}{ Região } & $\begin{array}{c}\text { Usinas } \\
\text { (ha) }\end{array}$ & $\begin{array}{c}\text { Destilarias } \\
\text { (ha) }\end{array}$ \\
\hline Ribeirão Preto & 7.752 & 5.358 \\
Piracicaba & 4.824 & 666 \\
Jaú e Araraquara & 10.450 & 1.900 \\
Arenito e V. Paranapanema & 5.420 & 2.514 \\
\hline Estado de São Paulo & 6.725 & 2.856 \\
\hline
\end{tabular}

Fonte: Dados da pesquisa.

A área média arrendada pelas usinas do Estado de São Paulo (Tabela 9) é cerca de 2,3 vezes maior do que a área média arrendada pelas destilarias, e a maior área média de arrendamento é de responsabilidade das usinas da região de Jaú e Araraquara.

Quanto aos valores de arrendamento, que podem ser vistos na Tabela 10 a seguir, percebe-se uma grande discrepância tanto dentro de cada região como entre regiões. 
Tabela 10. Valores de arrendamento em tonelada por hectare ao ano nas diversas regiões produtoras do Estado de São Paulo na safra $86 / 87$.

\begin{tabular}{lcc}
\hline \multirow{2}{*}{ Região } & \multicolumn{2}{c}{ Valor de arrendamento } \\
\cline { 2 - 3 }$(\mathrm{t} / \mathrm{ha} / \mathrm{ano})$ & Minimo & 45 \\
\hline Ribeirião Preto & 10 & 45 \\
Piracicaba & 9 & 40 \\
Jaú e Araraquara & 3 & 37 \\
Arenito e V. Paranapanema & 4 & \\
\hline
\end{tabular}

Fonte: Dados da pesquisa.

Pela Tabela 10 nota-se que $45 \mathrm{t} / \mathrm{ha} / \mathrm{ano}$ pagas como remuneração a terra arrendada è um valor bastante elevado, mas que apareceu mais de uma vez e em mais de uma região. Pelo questionário enviado, não se tem condições de se tirar maiores conclusões sobre estesvalores, mas talvez tais áreas sejam consideradas estratégicas para as U/D, ou ainda $\underline{a}$ reas de acionistas que, por uma politica adotada, podem receber uma melhor remuneração. Para efeito de ajustamento da regres são para cada região produtora, estes valores extremos não fo ram considerados.

Quanto aos principais fatores que são levados em consideração na hora de decidir sobre a remuneração do arrendamento, estes podem ser vistos na Tabela 11. 
Tabela 11. Fatores levados em consideração para remuneração do arrendamento no setor Sucro Alcooleiro do Esta do de São Paulo durante a safra $86 / 87$.

Fatores

Considerados

Nọ

- Fertilidade do solo

51

- Distância

- Operações já executadas na área

25

- Topografia

- Vias de acesso

- Outros

Fonte: Questionários

Conforme já esperado, o tipo de solo e a distân cia da unidade industrial foram os principais fatores levados em consideração para definir o valor do arrendamento.

\subsection{Anostragem}

De posse das informações obtidas atravēs do envio do questionário (Apêndice 1) a todas as unidades que pretendiam moer na safra $86 / 87$, procedeu-se a uma análise no senti- 
do de escolher aquelas unidades que mais se demonstravam dispostas a fornecer as informações julgadas importantes para o estudo em questão. Também foi realizado um contato telefônico, marcando uma entrevista com a pessoa responsável pelo arrenda mento de terras. Assim, o critério para definir quais unida des seriam "entrevistadas" foi a predisposição demonstrada pe las usinas e destilarias em colaborar com tal estudo.

Nestas unidades foi aplicado um outro questioná rio (Apêndice 2) que continha as questões sobre os contratos de arrendamento e dados individualizados das propriedades arrendadas.

O número de unidades industriais visitadas pes soalmente em cada região pode ser visto na Tabela 12. 
Tabela 12. Número de unidades entrevistadas pessoalmente nas regiões produtoras do Estado de são Paulo durante a safra $86 / 87$.

\begin{tabular}{lcc}
\hline \multicolumn{1}{c}{ Região } & $\begin{array}{c}\text { Número de unidades } \\
\text { cujos dados foram } \\
\text { aproveitados }\end{array}$ & $\begin{array}{c}\text { Número de } \\
\text { andades totais } \\
\text { amostradas }\end{array}$ \\
Ribeirão Preto & 4 & 6 \\
Piracicaba & 2 & 4 \\
Jaú e Araraquara & 3 & 9 \\
Arenito e v. Paranapanema & 4 & 26 \\
\hline
\end{tabular}

Fonte: Dados da pesquisa.

Do total das 26 amostradas, só foram aproveitạ das as informações referentes a 13 unidades, sendo que na região de Jaū-Araraquara e Piracicaba não se obtiveram dados re ferentes a destilarias. Essa redução em relação ao número das efetivamente entrevistadas se deveu a alguns motivos, enentre os quais:

- Critério adotado por algumas destilarias para cobrar o transporte da produção dos acionistas; nesse caso cada acionista se responsabiliza por uma determinada cota (quantidade de cana entregue na indústrial e o gasto com o transporte da 
produção de todos acionistas é rateado pela cota de cada um, independentemente das distâncias percorridas. Esse "frete mé dio" faz com que uma cana produzida a $50 \mathrm{~km}$ de distância, por exemplo, tenha para o acionista um mesmo custo de transporte de uma cana que seja produzida a $5 \mathrm{~km}$ de distância. Essa medida faz com que não haja diferenciação na remuneração das propriedades arrendadas a diferentes distâncias. E mesmo $\circ$ tipo de solo as vezes é desconsiderado. Este comportamento deve ser encarado como temporário e, com o passar dos anos, deve haver modificação neste processo. Isto porque este critério não leva a uma otimização do sistema e faz com que os acionistas com propriedades localizadas próximas das unidades industriais subsidiem aqueles com áreas mais distantes. Por este motivo as informações das destilarias que adotam esse critērio não foram consideradas;

- Falta de organização por parte de algumas usinas e destilariasi ē o caso de algumas unidades que apesar de terem demons trado boa vontade, não possuiam as informações detalhadas das propriedades quanto a fertilidade e distância;

- Proibição por parte da diretoria de fornecer informações so bre o arrendamento de terras; é o caso de unidades, cujos departamentos agrícolas possuiam as informações solicitadas mas foram proibidas de fornecê-las por ordens superiores.

Mesmo com todas as dificuldades citadas, foram conseguidas informações individualizadas referentes a 425 pro 
priedades distribuídas nas regiões produtoras do estado conforme Tabela 13 .

Tabela 13. Distribuição das propriedades arrendadas por região produtora de cana-de-açúcar do Estado de são Paulo durante a safra $86 / 87$.

\begin{tabular}{lc}
\hline Região & $\begin{array}{c}\text { Número de } \\
\text { propriedades }\end{array}$ \\
\hline Ribeirão Preto & 129 \\
Piracicaba & 57 \\
Jaú e Araraquara & 133 \\
Arenito e v. Paranapanema & 106 \\
\hline Total & 425 \\
\hline
\end{tabular}

Fonte: Dados da pesquisa.

São as informações referentes a essas 425 propriedades que possibilitaram estimar a remuneração das terras arrendadas em função do tipo de solo e da distância da unidade industrial. 
40 .

4. RESULTADOS E DISCUSSOES

Neste capitulo é realizada uma sintese das prin cipais cláusulas contidas nos contratos de arrendamento. São também apresentadas as regressões que estimam as remunerações das terras arrendadas, as remunerações dos produtores autônomos e as distâncias que nivelam a remuneração obtida com o a rendamento de terras com a remuneração obtida com a produção autônoma .

4.1. Clāusulas Principais dos Contratos de Arrendamento.

Primeiramente $\circ$ que deve ser destacado é que os contratos existentes são de fato, na maioria das vezes contra tos de parceria, apesar de também existirem contratos de arrendamento. E comum também haver os dois tipos de contratos simultaneamente. A explicação para tal fato é que na parceria o proprietário da terra permanece na condição de fornecedor, descontando de sua renda apenas os encargos fixados pe- 
lo IAA. Já no arrendamento, o proprietário da terra desconta um percentual de sua renda para fins de imposto de renda. E claro que a maioria prefere ficar na situação do primeiro grụ po.

Outro ponto, é que na condição de fornecedor, o proprietário de terra pode usufruir dos benefícios prestados pelas Cooperativas e Associações da classe, que além de prestar assistência técnica também prestam serviços no campo da assistência social.

Feito estas observações e apesar de haver uma certa heterogeneidade nos tipos de contratos, procurar-se-á destacar os pontos considerados comuns:

1. Partes Contratantes: geralmente o contrato é feito entre o proprietário da terra e uma agropecuária que pertence ao mesmo grupo da usina. E comum também, principalmente em des tilarias, os contratos serem feitos diretamente com os acio nistas, que são na realidade os donos da destilaria. Neste caso o nome da destilaria não aparece no contrato.

2. Prazo: apesar de grande variação, o prazo mais frequente é o de 5 anos com possibilidade de prorrogação por mais um corte.

3. Formas de Pagamento: este é um dos itens que mais apresen ta variações. A forma de pagamento varia na quantidade de to neladas de cana paga por hectare, na periodicidade e na referência do valor da tonelada de cana que pode ser o do campo ou o da esteira. 
Os valores minimos e máximos já foram mostrados na Tabela 10 do Capitulo 3. A periodicidade de pagamento chega em certos extremos a ser mensal apesar de o pagamento anual ser a forma mais frequente. Adiantamento de parcelas também podem aparecer. Com a implantação do pagamento de cana pelo teor de sacarose, algumas unidades também dão ao dono da terra uma participação no ágio que porventura a cana apresente. 4. Obrigações: em geral fica explícito que o arrendatārio de ve zelar pela conservação do solo e manutenção de estradas. 0 arrendador se compromete a dar preferência ao arrendatário se porventura ele desejar vender sua propriedade. Outros pontos de segurança para o arrendatário tais como, a citação de obrigar os herdeiros e sucessores a cumprir o estipulado no contrato e tambēm a autorização para a realização de empréstí mos bancários (não implicando è claro em hipoteca da terra) aparecem com frequência.

\subsection{Remuneração da Terra Arrendada}

Nas tabelas 14 a 17 a seguir serão apresentados as regṛessões que foram estimadas para as diversas regiões produtoras, conforme citado no capitulo 2 , item 2.3.1. 
43.

4.2.1. Região de Ribeirão Preto

Percebe-se (Tabela 14) que a regressão estimada se mostrou significativa ao nível de lo de probabilidade e que 41,10\% da variação ocorrida nos dados é explicada pela re gressão.

Tabela 14. Estimativa da remuneração da terra arrendada (t/ ha) no setor sucro alcooleiro para a região de $\mathrm{R} \underline{\underline{i}}$ beirão Preto durante a safra $86 / 87$.

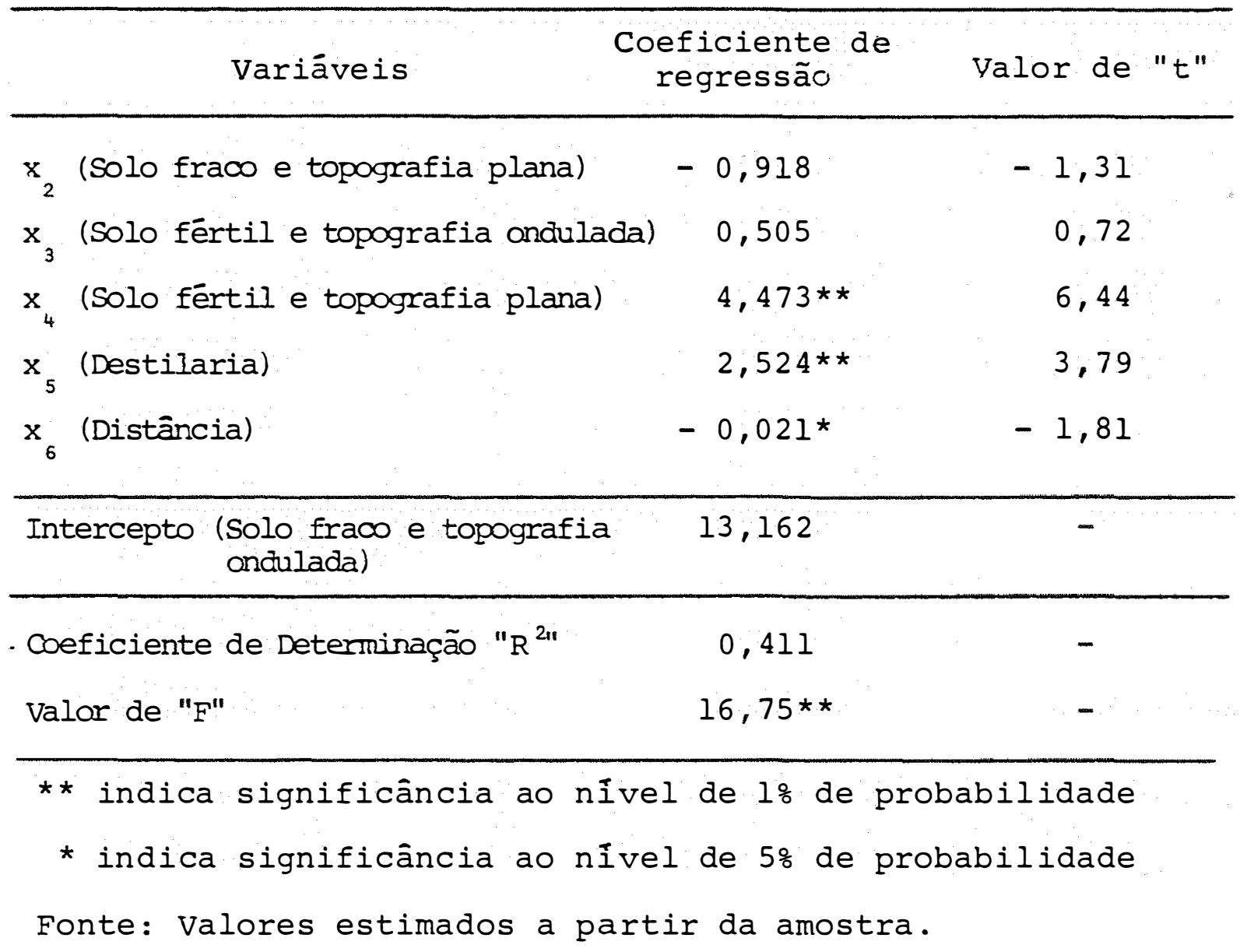


os valores obtidos pelo teste "t" mostram que as variāveis $x_{4}$ (solo fértil com topografia plana), $x_{5}$ (desti laria) são estatisticamente diferentes de zero ao nível de probabilidade de $1 \%$, enquanto que $x_{6}$ (distância) é significativamente diferente de zero ao nível de probabilidade de 58 .

Pode-se concluir que para a região de Ribeirão Preto não são levados em consideração para a remuneração das terras arrendadas os solos do tipo 2 e 3 , isto é, só foi cons tatado diferenciação marcante para solos considerados "roins", tipo 1, e solos considerados "bons", tipo 4.

Quanto a diferença na remuneração das terras ar rendadas, caso a unidade industrial seja usina ou destilaria, os resultados obtidos sugerem que as últimas estão melhor remunerando, porque a variāvel $x_{5}$ (destilaria) foi significativamente diferente de zero ao nível de 18 de probabilidade.

Este fato pode ser explicado pelo grande número de destilarias que foram instaladas nos últimos anos nessa re gião que já era tradicional na produção de cana-de-açúcar. Is to fica mais claro de visualizar olhando-se a Tabela 5 apresentada no início do capítulo 3, que mostra que das 39 unida des existentes na região, 19 são destilarias, que foram instaladas após o PROÁLCOOL. Assim, é razoável que as destilarias que ingressaram nesse setor posteriormente às usinas, pa ra conseguirem terra para arrendar e obterem matéria-prima para sua in 
dústria, paguem um pouco mais que as usinas, que já estavam instaladas e tinham contratos de arrendamento firmados a mais tempo.

Sobre a distância da unidade industrial ser levada em consideração na hora de decidir sobre a remuneração do arrendamento, apesar dos resultados obtidos mostrarem significância ao nível de $5 \%$ para essa variável, percebe-se que sua importância relativa é muito pequena. Pela estimativa do parâmetro obtido, para haver um decréscimo de 2,1 toneladas de cana pagas por hectare arrendado, é preciso que a propriedade arrendada se encontre a uma distância de $100 \mathrm{Km}$ da base industrial, o que na prática não ocorre, visto que a distância média e máxima encontrada para essa região foi de $49 \mathrm{Km}$ e $82 \mathrm{Km}$ respectivamente.

\subsubsection{Região de Arenito e Vale do Paranapanema}

Para essa região, cuja regressão estimada (Tabe la 15) também se apresentou significativa ao nível de l\% de probabilidade, e com coeficiente de determinação múltiplo, " $\mathrm{R}^{2} "$, de 0,743 , os valores obtidos pelo teste " $t$ " indicam que as variāveis $x_{2}$ (solo fraco de topografia plana), $x_{3}$ (solo fértil de topografia ondulada), $x_{4}$ (solo fértil de topogra fia plana) não são estatisticamente diferente de zero pelo me nos ao nível de $5 \%$ de probabilidade. 
As variāveis $x_{5}$ (destilaria) e $x_{6}$ (distância) de monstram ser estatisticamente diferentes de zero ao nível de $1 ․$

Tabela 15. Estimativa da remuneração da terra arrendada (t) ha) no setor sucro alcooleiro para a região de Are nito-Vale do Paranapanema durante a safra 86/87.

\begin{tabular}{|c|c|c|}
\hline Variāveis & $\begin{array}{l}\text { ficiente de } \\
\text { cegressão }\end{array}$ & Valor de " $t$ " \\
\hline$x_{2}$ (Solo fraco e topografia plana) - & $-1,424$ & $-1,52$ \\
\hline$x_{3}$ (Solo fértil e topografia onculada) & a) 0,412 & 0,45 \\
\hline$x_{4}$ (Solo fértil e topografia plana) & 0,588 & 0,62 \\
\hline$x_{5}$ (Destilaria) & $-5,336 * *$ & $-15,35$ \\
\hline$x_{6}$ (Distância) & $-0,064 * *$ & $-4,62$ \\
\hline $\begin{aligned} \text { Intercepto } & \text { (Solo frado e topogra- } \\
& \text { fia ondulada) }\end{aligned}$ & 17,189 & - \\
\hline Coeficiente de Determinação " $R$ " " & 0,743 & - \\
\hline Valor de " $F "$ & $57,86 * *$ & - \\
\hline
\end{tabular}

** indica significância ao nível de $1 \%$ de probabilidade Fonte: valores estimados a partir da amostra. 
O fato de os diferentes tipos de solos não se apresentarem estatisticamente diferentes de zero pode ter acontecido pelo fato da região do Arenito não apresentar uma diferenciação marcante de tipo de solo, sendo que os cultivados com cana-de-açúcar seguem quase que um mesmo padrão. Assim, para essa região não houve variabilidade suficiente para ser captado pelo instrumental estatístico utilizado. Aqui, ao contrário do que ocorreu na região de Ribeirão Preto, as destilarias estão pagando menos pela terra arrendada do que as usinas, porque 0 valor da variável $x_{5}$ na regressão estimada foi negativo. Isto pode ser explicado se levarmos em consideração que as destilarias que foram aí instaladas, não entraram em disputa por terras com as usinas, e sim instalaramse em āreas mais afastadas e antes ocupadas, na sua maioria, com pastagens. Assim, uma possivel justificativa para uma menor remuneração das terras arrendadas por parte das destila rias pode ser devido a baixa remuneração das terras arrenda das para pastagens. Segundo PROGNOSTICO (1986) em junho de 1986 o valor médio para o aluguel de pasto nas diras de Bauru, são José do Rio Preto, Araçatuba, Presidente Prudente, Ma rilia foi de $C z \$ 1.076,80$ por hectare, o que transformados em toneladas de cana dariam cerca de 11 toneladas, que é um valor próximo daquele pago pelas destilarias. Aqui deve-se observar que o arrendamento para cana-de-açúcar é um arrendamento da terra, ao contrário das pastagens, que exige uma forma ção de pasto. Assim, mesmo com valores semelhantes, deve ser 
mais vantajoso para o proprietário da terra arrendar suas ter ras para a cana do que para pastagens.

Finalmente, a variāvel distância, também é leva da em consideração na hora de decidir sobre a remuneração das terras arrendadas, sendo que aqui também sua participação relativa é baixa. Para cada $100 \mathrm{Km}$ de distância da unidade industrial há um decréscimo de 6,4 toneladas pagas por hectare arrendado, sendo que a distância média encontrada para essa região foi de $25 \mathrm{Km}$ e a máxima de $49 \mathrm{Km}$.

\subsubsection{Região de Jaū e Araraquara}

Percebe-se (Tabela 16) que apesar da regressão estimada ser significativa ao nivel de $1 \%$ de probabilidade 0 valor do coeficiente de determinação múltipla, " $R^{2}$ ", apresentou o valor de 0,37 . 
Tabela 16. Estimativa da remuneração da terra arrendada ( $t$ ) ha) no setor sucro alcooleiro para a região de Jaü-Araraquara durante a safra $86 / 87$.

\begin{tabular}{lcc}
\hline Variáveis & $\begin{array}{c}\text { Coeficiente de } \\
\text { regressão }\end{array}$ & Valor de "t" \\
\hline$x_{2}$ (Solo fraco e topografia plana) & $-1,350$ & $-1,85$ \\
$x_{3}$ (Solo fértil e topografia ondulada) & $1,540 *$ & 1,98 \\
$x_{4}$ (Solo fértil e topografia plana) & $4,339 * *$ & 5,58 \\
$x_{6}$ (Distâncía) & 0,006 & 0,18 \\
\hline Intercepto (Solo fraco e topogra- & 10,639 & - \\
\hline fla ondulada) & 0,371 & - \\
Coeficiente de Determinação " $R^{2} "$ & $18,89 * *$ \\
Valor de "F" & 0
\end{tabular}

** indica significância ao nível de $1 \%$ de probabilidade

* indica significância ao nível de $5 \%$ de probabilidade Fonte: Valores estimados a partir da amostra.

Os valores obtidos pelo teste " $t$ " indicam que as variáveis $\mathrm{x}_{3}$ (solo fértil com topografia ondulada), $\mathrm{x}_{4}$ (so lo fértil com topografia plana) são estatisticamente diferen tes de zero ao nivel de probabilidade de $5 \%$ e $1 \%$ respectivamente, enquanto que as demais, $x_{2}$ (solo fraco com topografia plana) e $x_{6}$ (distância) não se mostravam estatisticamente diferentes de zero nem a um nivel de $5 \%$ de probabilidade. 
Parece haver uma coerência por parte das usi nas quanto a diferenciação dos tipos de solo, pois há nesta região um predomínio dos grupos de solo, terra roxa estrutura da e latossolos, sendo ambos de fertilidade boa mas os perten centes ao segundo grupo apresentam uma melhor topografia.

$$
\text { Quanto a variável } x_{6} \text { que representa a distância }
$$

das áreas arrendadas às usinas, esta não se mostrou estatistí camente diferente de zero e tal fato pode ter ocorrido devido a pouca variabilidade ocorrida nessa variável, sendo que a distância média encontrada para essa região foi de $12 \mathrm{~km}$ e a máxima de $29 \mathrm{~km}$.

\subsubsection{Região de Piracicaba}

Para a região de Piracicaba (Tabela 17), nem a regressão estimada nem as variáveis que compunham a regressão se apresentaram diferentes estatisticamente de zero a um nivel de 5\% de significância. 
Tabela 17. Estimativa da remuneração da terra arrendada ( $t$ / ha) no setor sucro alcooleiro para a região de $\mathrm{Pi}$ racicaba durante a safra $86 / 87$.

\begin{tabular}{lcc}
\hline Variáveis & $\begin{array}{c}\text { Coeficiente de } \\
\text { regressão }\end{array}$ & Valor de "t". \\
\hline$x_{2}$ (Solo fraco e topografia plana) & $-1,719$ & $-1,12$ \\
$x_{3}$ (Solo fértil e topografia onđulada) & $-0,088$ & $-0,06$ \\
$x_{4}$ (Solo fértil e topografia plana) & 0,564 & 0,40 \\
$x_{6}$ (Distância) & $-0,058$ & $-1,55$ \\
\hline Intercepto (Solo fraco e topogra- & 17,062 & - \\
fia ondulada) & & - \\
Coeficiente de Determinação " ${ }^{2} "$ & 0,097 & - \\
Valor de "F" & 1,40 & - \\
\hline
\end{tabular}

Fonte: Valores estimados a partir da amostra.

Em contato com os agrônomos de algumas unidades dessa região, foi constatado que existem elementos contratados por algumas usinas que ficam nas portas de outras e oferecem um melhor preço para a tonelada de cana aos fornecedores que aí fazem fila para entregar a sua produção. Este fato retrata a competição que existe entre as diversas unidades.

Essa competição talvez possa estar agindo de 
forma a se sobrepor nas variáveis solo e distância da unidade industrial. Também não pode ser descartada a possibí lidade de erro na amostragem, pois nessa região só se pode contar com a colaboração de 2 usinas.

4.3. Remuneração do Produtor Autōnomo Proprietārio da Terra

No cálculo desta remuneração, foram considerados dois tipos de fornecedores: o primeiro tipo (tipo I) possui uma produtividade de área plantada de 62,54 tonelada por hectare que foi a produtividade média encontrada pela ORPLANA (1986) em seu estudo de custo de produção. Para esse produtor sua remuneração é dada por:

$$
\begin{aligned}
\mathrm{RPI}= & 62,54 \cdot 108,6]-\{3208,64+[343,97+30,39 \mathrm{D}]+ \\
& +1663,97+838,17\} \\
\mathrm{RPI}= & 737,09-30,39 \mathrm{D}
\end{aligned}
$$


onde:

$$
\begin{aligned}
\mathrm{RPI} & =\text { remuneração do produtor tipo I em } \mathrm{C} z \$ / \\
\text { ha: } \mathrm{D} & =\text { distância em } \mathrm{Km} \text { da usina ou destilaria. }
\end{aligned}
$$

No cálculo do preço da tonelada de cana foi considerado um ágio médio de $15 \%$.

$$
\text { o segundo tipo de produtor (tipo II) tem uma }
$$
produtividade 208 superior ao anterior, ou seja, 75,05 t/ha de área plantada, mas com os mesmos custos fixos. Tal procedimento visa contemplar o produtor mais eficiente e que obtem algum tipo de economia, ou que esteja situado em um melhor tí po de solo. A remuneração desse produtor ficará:

$$
\begin{aligned}
\text { RPII }= & 75,05 \cdot 108,60-\{3438,33+[412,78+36,47 D]+ \\
& +1663,97+838,17\}
\end{aligned}
$$

ou

$\operatorname{RPII}=1797,18-36,47 \mathrm{D}$

onde :

$$
\begin{aligned}
\text { RPII } & =\text { remuneração do produtor tipo II em } \mathrm{Cz} \$ / \mathrm{ha} ; \\
D & =\text { distância em }
\end{aligned}
$$

No cálculo do preço da tonelada de cana foi considerado um á gio médio de $15 \%$. 
4.4. Determinação da Distāncia à Unidade Industrial que. Nivela a Remuneração Obtida com o Arrendamento de Terras com a Produção Autônoma.

Para se determinar a distância que nivela a remuneração do produtor autônomo com a remuneração obtida com $\circ$ arrendamento de terras, basta que se iguale as duas remunera ções, o que é feito nos itens 4.4.1. a 4.4.3. a seguir.

Como as remunerações dos dois tipos de produtores autônomos estão em $\mathrm{C} z \$ / \mathrm{ha}$, para que seja possivel tal com paração, antes é preciso transformar RPI e RPII em toneladas/ ha, o que é feito dividindo estas pelo valor da tonelada de cana, que na época do estudo era de $\mathrm{C} z \$ 94,44$.

4.4.1. Região de Ribeirão Preto

A remuneração em $t /$ ha do produtor autônomo tipo I, proprietário da terra é dada por $\mathrm{RPI}_{t}$.

$$
R P I_{t}=7,805-0,322 \mathrm{D}
$$

A remuneração em $t /$ ha do produtor autônomo tipo II è dada por RPII $I_{t}$. 


$$
\operatorname{RPII}_{t}=19,030-0,386 \mathrm{D}
$$

Por outro lado, a remuneração estimada para 0 arrendamento das terras dessa região em $t /$ ha è dada por ${ }_{\mathrm{RP}} \cdot$

$R A_{R P}=13,162-0,918 x_{2}+0,505 x_{3}+4,473 x_{4}+2,524 x_{5}-0,021 x_{6}$

Igualando-se $\mathrm{RPI}_{t}$ com $\mathrm{RA}{ }_{\mathrm{RP}}$ para se determinar a distância que nivela as remunerações obtidas com ambos os sis temas de exploração (arrendamento e produção autônoma), perce be-se que esta será negativa indiferentemente se 0 arrendamen to é realizado por usina ou destilaria e também indiferentemente do tipo de solo em que a propriedade se encontra. Isto significa que para o produtor considerado tipo I, ou seja, que possui uma produtividade agrícola de ārea plantada de 62,44t sempre será mais vantajoso arrendar sua terra do que produzir por conta própria, e deve dar preferência para o arrendamento feito por destilarias quando houver possibilidade.

Quando se compara a remuneração do produtor tipo II ( $\mathrm{RPII}_{t}$ ) com a remuneração obtida com o arrendamento ( $\mathrm{RA}_{\mathrm{RP}}$ ) para se calcular a distância que nivela a remuneração em ambos os sistemas tem-se as seguintes situações: 
56.

a.) Se o solo de sua propriedade for classificado pela U/D de baixa fertilidade e topografia onjulada, será mais vantajoso ele produzir por conta própria até a distância de $16,06 \mathrm{Km}$ se a unidade industrial for usina; se for destilaria até 9,2 Km b.) Se o solo de sua propriedade for considerado fértil e de topografia plana, será mais vantajoso ele produzir por conta própria até a distância de $3,82 \mathrm{Km}$ caso a unidade industrial que queria arrendar sua terra seja usina. Em distâncias superiores o arrendamento é mais vantajoso. Se for destilaria sem pre será mais vantajoso arrendar para esta indiferente da distância.

c.) Para propriedades com outros tipos de solo (fraco com topo frafia plana e fértil com topografia ondulada), como seus coeficientes não se mostraram estatisticamente significativos na regressão estimada, pode-se aceitar que as distâncias que nivelam as remunerações sejam próximas do caso $a$, ou seja,16,06 $\mathrm{Km}$ se a unidade industrial for usina ou $9,2 \mathrm{~km}$ se for destilaria.

\subsubsection{Região de Arenito e Vale do Paranapanema}

Para essa região a remuneração obtida com 0 arrendamento de terras em $t /$ ha è dada por ${ }_{R A} A_{A P}$.

$$
\mathrm{RA}_{\mathrm{AVP}}=17,189-1,424 \mathrm{x}_{2}+0,412 \mathrm{x}_{3}+0,588 \mathrm{x}_{4}-5,336 \mathrm{x}_{5}-0,064 \mathrm{x}_{6}
$$


Igualando-se $\mathrm{RA}_{\mathrm{AVP}}$ com a remuneração obtida com a produção autônoma do produtor tipo I ( $R P I_{t}$ ) para se achar a distância que nivela ambas remunerações, tem-se que esta será negativa. Isto significa que sempre será mais vantajoso arrendar sua terra para a usina ou destilaria do que produzir por conta própria. Pelos resultados obtidos pela regressão, deve-se dar preferência para o arrendamento feito pelas usinas. Este resultado independe do tipo de solo ou da distância da unidade industrial.

Adotando-se procedimento análogo para o produtor autônomo considerado tipo II, tem-se que, se sua propriedade for classificada pela usina como de solo fraco com topografia ondulada será mais vantajoso ele arrendar para a usina somente se estiver a distâncias maiores do que 5,71 $\mathrm{Km}$. Se o a $\underline{\underline{r}}$ rendamento for feito por destilarias, tal distância passa para $22,27 \mathrm{Km}$. Em distâncias inferiores é mais vantajoso a produção autônoma. Como para essa região o modelo ajustado não apresentou diferença estatisticamente significativa na remuneração dos outros tipos de solo (fraco com topografia plana, fértil com topografia ondulada, fértil com topografia plana) pode-se aceitar que ạs distâncias encontradas acima também seriam aproxinadamente vallidas para propriedades que apresentam estes solos.

\subsubsection{Região de Jaú e Araraquara}

Para essa região a remuneração obtida com o ar- 
rendamento de terras em $t /$ ha é dada por $R_{J A}$.

$$
\mathrm{RA}_{\mathrm{JA}}=10,639-1,350 \mathrm{x}_{2}+1,540 \mathrm{x}_{3}+4,339 \mathrm{x}_{4}-0,006 \mathrm{x}_{6}
$$

Igualando-se RA JA com a remuneração obtida com a produção autōnoma do produtor tipo I em $t / h a\left(R P I_{t}\right)$, a fim de se determinar a distância que nivela as remunerações, percebe-se que esta será negativa, significando que também para essa região, independentemente do tipo de solo e distân cia, sempre será mais vantajoso arrendar a terra para a usina.

De modo análogo, quando se compara a remuneração obtida com o arrendamento em t/ha ( $\left.\mathrm{RA}_{J A}\right)$ com a remuneração obtida pelo produtor tipo II ( $\left.R P I I_{t}\right)$ tem-se os seguintes casos:

a.) Se seu solo for classificado pela usina como de baixa fer lidade e topografia ondulada somente será mais vantajosa a produção autônoma e a entrega na usina, em distâncias inferio res a 22,07 km. Esta distância também serve aproximadamente para as propriedades que possuam o tipo de solo de baixa fertilidade e topografia plana.

b.) Se seu solo for considerado de boa fertilidade com topografia ondulada será mais vantajosa a produção por conta própria em distâncias até $18,02 \mathrm{Km}$.

c.) Se seu solo for considerado de boa fertilidade e boa topo 
grafia, será mais vantajosa a produção por conta própria até a distância de 10,66 $\mathrm{km}$ da usina. Em distâncias maiores será mais vantajoso o arrendamento.

4.4.4. Região de Piracicaba

Pelo fato de não se ter conseguido um bom ajustamento da regressão na remuneração das terras arrendadas, pa ra essa região não é possível determinar tal distância. 
60.

5. CONCLUSOEES

Os resultados obtidos mostram um nitido favorecimento do sistema de arrendamento quando comparado ao sistema de produção autônomo. Nos diversos casos enfocados, quase sempre, só foi mais vantajoso a produção por conta própria em locais muito próximos da unidade industrial, locais estes que na prática já devem pertencer as U/D ou estar arrendado por elas.

E conveniente lembrar que durante a safra $86 /$ 87, época do levantamento dos dados, ocorreu a implantação do chamado plano cruzado, que congelou os preços vigentes em 29/02/86. Segundo PROGNÓSTICO (1986) enquanto a produção in dustrial obteve ganhos expressivos, a agricultura não pode acompanhar esse desempenho, pois estimativas de preço e produ ção dos principais produtos agrícolas do Estado de são Paulo mostram o pior resultado desde 1975/76. O próprio custo de produção estimado pela ORPLANA (1986), já alertava para a defazagem entre $\circ$ preço congelado e o estimado em tal estudo. 
Assim, os resultados encontrados podem naturalmente, mudar com as variações nos preços relativos considerados. Mas deve-se notar que mesmo considerando um fornecedor com uma produtividade significativamente maior do que a média do Estado de são paulo (produtor tipo II) os resultados ainda indicam o favorecimento do arrendamento em muitos casos. Isso ocorre provavelmente pela maior eficiência das U/D devido a maior es cala de produção, porque se as usinas ou destilarias, conseguem pagar ao proprietário da terra uma remuneração maior do que ele obteria produzindo por conta própria, é porque elas realmente possuem alguma fonte de economia. Logo, para o pro prietário de terras que se encontra no setor e procura maximi zar o seu lucro e também minimizar seus riscos, o arrendamento da sua terra quase sempre é opção mais lucrativa. Este fa to pode explicar o porque do decréscimo ocorrido nos últimos anos, na participação da classe de fornecedores no total da produção agrícola no Estado de são Paulo. Sabe-se no entanto, que muitas vezes o proprietário da terra arrendada continua aparecendo no contrato legal como fornecedor de cana e a maioria dos estudos realizados com base no mapa de fornecedores das usinas quase sempre super estimam a sua participação no setor. Este fato merece ser levado em consideração na hora de se definir uma politica agrícola.

O arrendamento de terras è uma prática bastante generalizada, e realizada pela maioria das unidades que opera ram na safra 86/87. A área arrendada declarada foi de 
450.027 ha, que representa cerca de $20 \%$ da área plantada com tal cultura mas suspeita-se que tal ārea esteja sub-estimada. Quanto à racionalidade das U/D no sentido de re munerar as terras arrendadas, os dados obtidos mostram que existe uma certa coerência, ou seja, terras de melhor qualida de são melhor remuneradas. A região de Ribeirão Preto foi a que apresentou maior variação absoluta na remuneração dos diferentes tipos de solo. Tal variação do pior para o melhor solo foi de 4,47 toneladas por ha ano. Para a região de Jaú, tal variação chegou a 4,33 toneladas por hectare ano. Já a região do Arenito e Vale do Paranapanema, pela própria homoge neidade quanto ao tipo de solo cultivado com cara-de-açúcar, praticamente não acusou variações. Para a região de Piracica ba, o ajustamento da regressão não permitiu se obter conclusões confiáveis.

o fator distância da unidade industrial também é considerado nas remunerações das terras arrendadas para as regiões de Ribeirão Preto e do Arenito e Vale do Paranapanema mas com uma importância relativa muito pequena, ou seja, as U/D não imputam o verdadeiro valor do custo de transporte de produção na redução da remuneração destas. Percebe-se que o coeficiente que reduz a remuneração das terras arrendadas em função da distância, è em média para estas duas regiões, cerca de 7 vezes menor do que o coeficiente que reduz a remunera ção do produtor tipo I em função da distância das U/D, e 9 ve zes menor do que o coeficiente calculado para o produtor tipo 
II.

Destaca-se também que para as regiões de JaúAraraquara e Piracicaba o fator distância não se apresentou estatisticamente diferente de zero. Isto indica um forte fator de equalização na remuneração das terras arrendadas.

Quanto ao fato do arrendamento ser um dos agentes colaboradores para a concentração de terras nas maos das U/D os resultados obtidos mostraram o contrário. Se com o a rendamento, o proprietário da terra aumenta sua renda, então ele terá menos pressão para vender a terra do que se estivesse produzindo por conta própria, podendo até retardar a venda desta. Se a concentração de terras do setor é alta, isto deve-se a outros motivos e não deve ter a contribuição da prátî ca do arrendamento. 
64.

6. LITERATURA CITADA

AZEVEDO FILHO, A.J.B.Y. \& BARROS, G.S.A.C. Impacto do Progra ma Nacional do Alcool - PROALCOOL sobre o mercado de traba lho rural no Brasil. In: CONFERENCIA LATINOAMERICANA DE ECONOMIA AGRICOLA, Piracicaba, 1984. p. 1-38.

BESKOW, P.R. Caracteristicas gerais e recentes da economia do arroz no Rio Grande do Sul. In: ___. O arrendamen-. to capitalista na agricultura. São Paulo, Hucitec, 1986. p. 117-37.

BRANDÃO, A.S.P. O preço da terra no Brasil; verificação de algumas hipóteses. Rio de Janeiro, EPGE/FGV, 1986. 86 p.

CALDEIRA, C. Arrendamento rural no Brasil. Observador Econômico e Financeiro, Rio de Janeiro, 28 (172):57-62, 243-4, 1950 .

CALDEIRA, C. Prrendamento e parceria no Brasil. Rio de Janeiro. Comissão Nacional de Politica Agrária, 1955. 65 p. 
CARON, D., coord. Levantamento de dados básicos sobre os fornecedores de cana-de-açúcar; Estado de são Paulo. Pira cicaba, IAA/PLANALSUCAR.ASES, 1984. v.2 e 4.

CARON, D. Caracterização da agricultura familiar em diferentes áreas agrárias onde predominam atividades agropecuárias voltadas à exportação; cana-de-açúcar. In: SEMINĂRIO SOBRE A PESQUISA E O PEQUENO PRODUTOR NAS REGIÕES DE AGRICULTURA DE EXPORTAÇÃO, Ilheus, 1986. Itabuna, CEPLAC/CEPEC/ DISEC, 1986. p. 1-17.

CARON, D. \& PINAZZA, A.H. Cooperativas, Associações e Assistência técnica aos fornecedores de São Paulo. Saccharum $\underline{A P C}$, São Paulo, $\underline{9}(42): 20-39,1986$.

CENSO AGROPECUÁRIO; São Paulo. Rio de Janeiro, 1984 .

CHABARIBERY, D. \& MELLO, N.T.C. Comparação entre os coeficientes fisicos e estimativas de custos operacionais de produção da cana-de-açúcar própria de usina e fornecedor autô nomo, estado de São Paulo, safra 1980/81. Informações Eoonômicas, São Paulo, 10:19-28, 1980.

CLINE, W.R. Prognóstico dos efeitos de uma reforma agrária na produção agropecuária; o caso brasileiro. Boletim ABRA, Campinas, (7):23-42, 1974 .

FERREIRA, L.R. da Parceria e risco na agricultura do Nordeste. Rio de Janeiro, IPEA/IMPES, 1979. 230 p.

FUNDAÇÃO GETULIO VARGAS. Renda da terra. In: __. Subsí dios para fixação dos preços da cana-de-açúcar; safra 198485. Rio de Janeiro, 1984. p. 153. (Convênio IAA/FG/IBRE). 
GARCIA, A.E.B. Arrendamento e parceria agricola no Estado de São Paulo; 1920-69. São Paulo, IEA, 1982. 62 p. (Relató rio de Pesquisa, 04).

HOFFMANN, R. Economias de escala na produção de cana-de-açū car. Reforma Agrāria, Campinas, 11(1):32-6, 1984.

IAA/PLANALSUCAR. Projeto estimativas e acompanhamento de safras; região centro-sul e norte-nordeste II. Araras, 1985. n.p. (Relatório Regional, $02-85 / 86$ ).

IAA/PLANALSUCAR. SOcio-Economia e Estatistica. In: Relatório Anual 1985. Piracicaba, 1986. p. 13-8.

MANOEL, A. Política agrícola, eficiência e concentração na agricultura brasileira; um estudo do setor canavieiro paulista. São Paulo, 1985. 222 p. (Doutoramento - Faculdade de Economia e Administração/USP).

MARGARIDO, L.A.C. Diferenças na remuneração do produtor de cana-de-açúcar em função da distância à unidade industrial. Brasil Açucareiro, Rio de Janeiro, 104(3/4):8-10, 1986.

OLIVEIRA, J.T. \& COSTA, I.D.N. Evolução recente do preço da terra no Brasil; 1966-74. Revista de Economia Rural, São Paulo, 15:259-73, 1977 .

ORPLANA. Anuārio ORPLANA. São Paulo, 1985. 28 p.

ORPLANA. Custos de produção de cana-de-açūcar a nivel de fornecedores do Estado de São Paulo. São Paulo, 1986. 66 p. 
PINAZZA, A.H. \& PELIN, E.R. Uma análise crítica da produtiví dade na agroindústria canavieira. In: CONGRESSO NACIONAI DA SOCIEDADE DOS TECNICOS AÇUCAREIROS E ALCOOLEIROS DO BRA SIL, 2, Rio de Janeiro, 1981. Anais. Rio de Janeiro, STAB, 1981. v. 1, p. 319-51.

PINHEIRO, F.A. \& REYDON, B.P. O preço da terra e a questão a gräria; algumas eviđências impíricas relevantes. Revista de Economia Rural, Brasilia, 19:6-15, 1981.

PROGNOSTICO 85/86, São Paulo, I2:185-188, 1985.

PROGNOSTICO 86/87, São Paulo, 15:11, 93-102, 1986.

RAMOS, P. Um estudo da evolução e estrutura da agroindústria canavieira do Estado de São Paulo; 1930-82. São Paulo,1983. 167 p. (M.S. - Escola de Administração e Economia de São Paulo/FGV).

SAYAD, J. Especulação em terras rurais; efeitos sobre a produção agrícola e o novo ITR. Pesquisa e Planejamento Econōmico, Rio de Janeiro, 12:87-108, 1982.

VEIGA FILHO, A.A.; GATTI, E.U.; MELLO, N.T.C. O Programa Nacional do Álcool e seus impactos na agricultura paulista. Estudos Econômicos, São Paulo, 11:61-82, 1981. 
$6 \varepsilon$.

APENDICE 1 
Com o objetivo de subsidiar estudos a serem rea lizados pela DRSE/COSUL, referente ao aspecto de arrendamento de terras no setor sucro-alcooleiro, solicitamos o preenchimento das informações abaixo.

NOME DA USINA/DESTILARIA:

1) A Usina/Destilaria arrenda terras de terceiros?

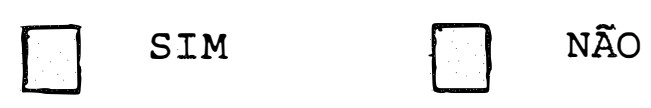

2) Em caso afirmativo, qual o total da àrea em ha que é arren dada pela unidade?

Ârea : ha

3) Quais os valores mínimo e māximo pago aos proprietārios das terras arrendadas, em toneladas de cana por ha?

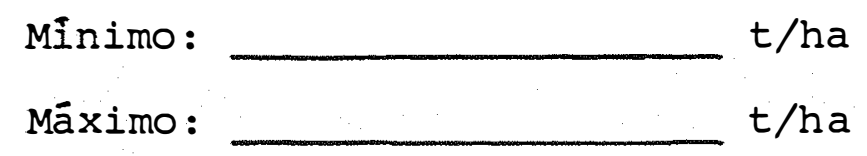

4) Como os valores acima são definidos? Resp.:

NOME DO INFORMANTE : FUNÇÃO : 
70.

APENDICE 2 
SISTEMA DE ARRENDAMENTO DE TERRAS NO SETOR SUCRO-ALCOOLEIRO DO ESTADO DE SÃO PAULO

Usina/Destilaria:

Data:

Informante:

Area total arrendada (ha):

1. Qual o nümero de propriedades arrendadas?

2. Quantos arrendadores existem?

2.1. Os contratos de arrendamento são:
( ) verbal
( ) escrito

3. Principais clāusulas:

4. Duração média (anos) dos contratos de arrendamento:

5. A época de pagamento ao proprietário é pré-fixado?
( ) $\operatorname{sim}$
( ) não 
5.1. Em caso positivo, qual?

5.2. Em caso negativo, em que época do ano a U/D costuma pạ gar ao proprietário:

( ) começo do ano

( ) começo da safra

( ) meio da safra

( ) final da safra

( ) outra, qual?

5.3. A forma de pagamento é parcelada?
( ) $\operatorname{sim}$
( ) não

6. O valor da tonelada é o:
( ) no campo
( ) na esteira
( ) outro, qual?

6.1. Qual a maior distância que a unidade industrial arrenda terra? Qual a ārea arrendada nesse caso?

6.2. Quando há vários preços da tonelada de cana, em um ano qual o preço pago ao proprietário da terra?

7. Com o PCTS houve alguma mudança nos contratos de arrendamentọ?

( ) sim, qual?

8. A conservação dos solos nas áreas arrendadas é feita da mesma maneira do que a da U/D? 
9. E aplicado vinhaça nas āreas arrendadas?
() $\operatorname{sim}$
( ) não

10. Qual a menor área arrendada (ha)?

11. Qual a maior àrea arrendada (ha)?

12. Qual a área do arrendamento (ha)?

13. Aproximadamente, classificar os contratos de arrendamentos de acôrdo com:

Åreas:

Atè 5 ha:

De 5 a 50 ha:

De 50 a 500 ha :

Mais de 500 ha:

Total:
Porcentagem:

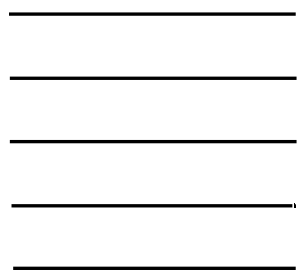

14. Utilizando-se da seguinte classificação para solos:

1 = solo fraco, topografia ondulada;

2 = solo fraco, topografia plana;

3 = solo fértil, topografia ondulada;

4 = solo fértil, topografia plana. 


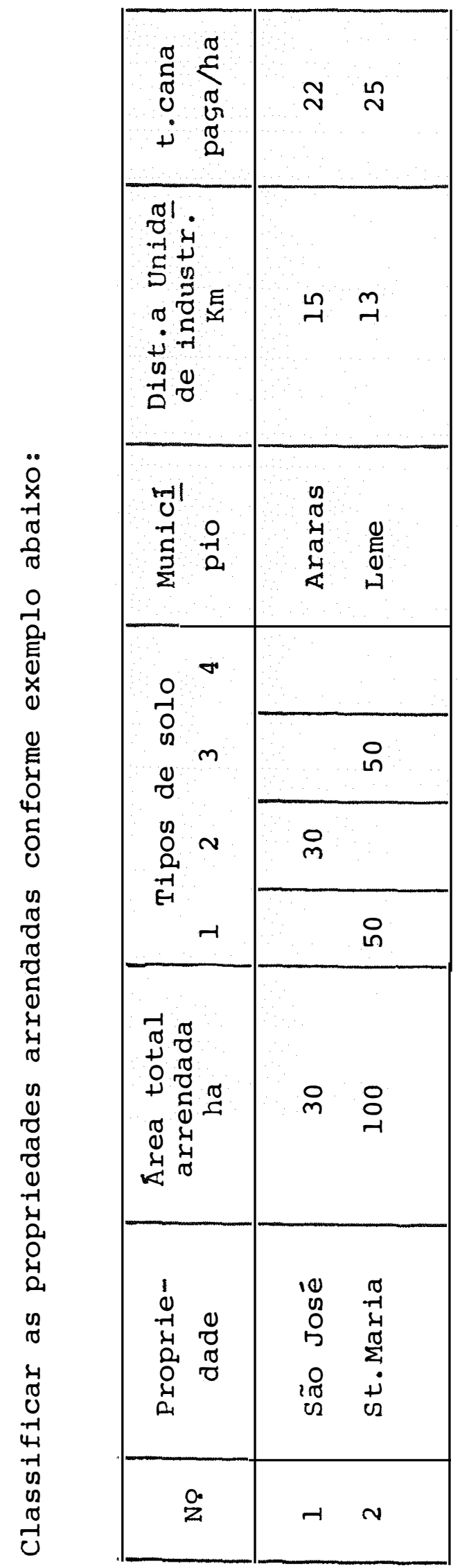

